\title{
U235: A Gamma Ray Analysis Code for Uranium Isotopic Determination
}

\author{
DeLynn Clark
}

December 1996

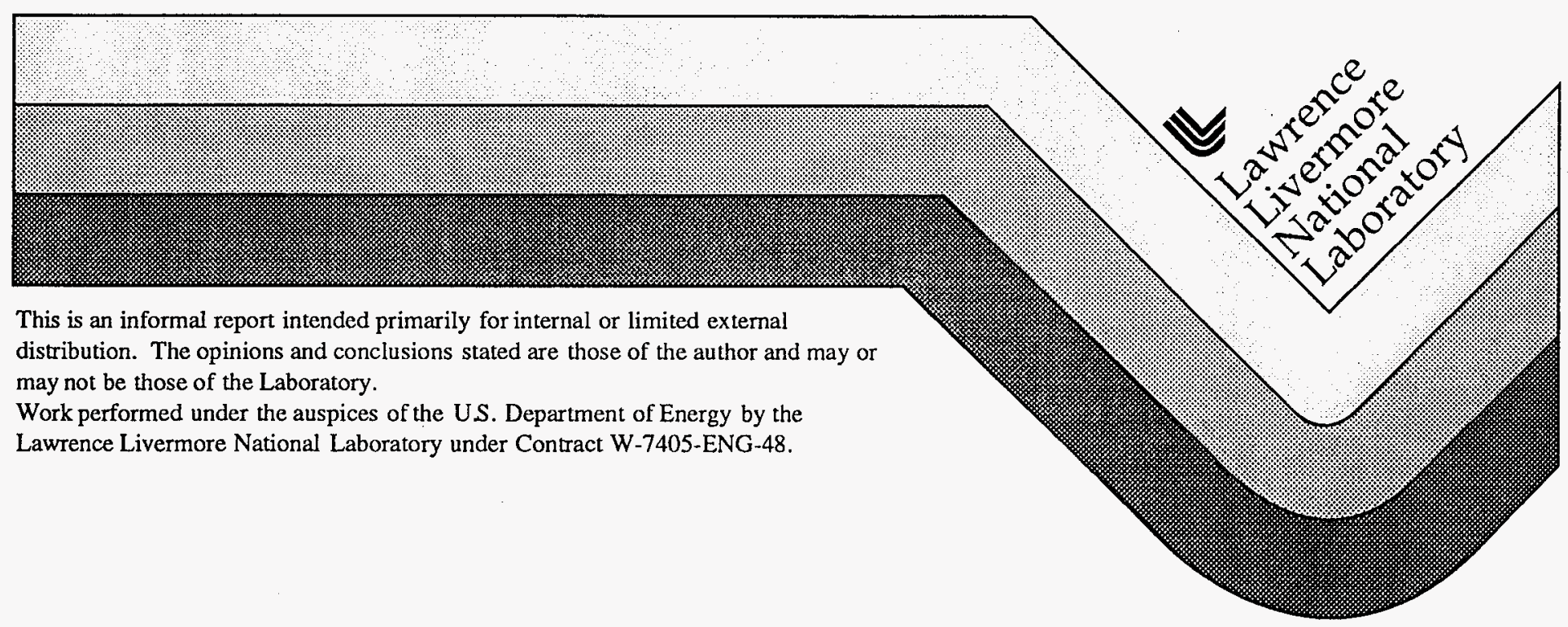




\section{DISCLAIMER}

This document was prepared as an account of work sponsored by an agency of the United States Government. Neither the United States Government nor the University of California nor any of their employees, makes any warranty, express or implied, or assumes any legal liability or responsibility for the accuracy, completeness, or usefulness of any information, apparatus, product, or process disclosed, or represents that its use would not infringe privately owned rights. Reference herein to any specific commercial products, process, or service by trade name, trademark, manufacturer, or otherwise, does not necessarily constitute or imply its endorsement recommendation, or favoring of the United States Government or the University of California. The views and opinions of authors expressed herein do not necessarily state or reflect those of the United States Government or the University of California, and shall not be used for advertising or product endorsement purposes. 


\title{
U235: A Gamma Ray Analysis Code for Uranium Isotopic Determination
}

\author{
DeLynn Clark \\ Isotope Sciences Division \\ Lawrence Livermore National Laboratory \\ University of California
}

December 1996

\begin{abstract}
:
A $235 \mathrm{U}$ analysis code, $\mathrm{U} 235$, has been written that can nondestructively determine the percentage of $235 \mathrm{U}$ in a uranium sample from the analysis of the emitted gamma rays. The code is operational and work is now underway to improve the accuracy of the calculation, particularly at the high $(>90 \%)$ and low $(<0.7 \%){ }^{235} \mathrm{U}$ concentrations. A technique has been found to evaluate low ${ }^{235} \mathrm{U}$ concentrations that works well on the existing standards. Work is now under way to evaluate this technique for other detectors and other types of samples. Work is also proceeding on: (1) ways to better determine gamma backgrounds, (2) techniques to determine the equivalent thickness of the sample to correct for gamma attenuation, (3) evaluation of the existing data base of branching ratios of $235 \mathrm{U}, 238 \mathrm{U}$ and their daughters gamma rays to allow better results and (4) evaluation of the existing data base on the emission ratios for uranium, thorium, and protactinium $\mathrm{x}$-rays.
\end{abstract}

\section{Introduction:}

Gamma ray spectrometry can be used to analyze uranium isotopic abundance ratios. The "standard" uranium enrichment meter relies on making standards of the various sample types of interest. Analyzing these standards with mass spectrometry to find the appropriate calibration factors is then done to calibrate out all the unknowns in the counting scheme. Then the strong ${ }^{235} \mathrm{U}$ gamma peak at $185.712 \mathrm{keV}$ can be counted with a "simple" two channel analyzer to find the peak counts and background. The net 185.715 counts are used to calculate the enrichment. This technique works well but has the draw back that new "standards" have to be made for each different geometry and analyzed by mass spectrometry. This calibration process is often very time consuming and costly as well as being limited to "calibrated" geometries.

Accurate analysis of a radioactive sample by high resolution Germanium detector spectrometry requires correct information on the gamma ray and $x$-ray branching ratios for the radionuclides in the sample. ${ }^{235} \mathrm{U}$ and ${ }^{238} \mathrm{U}$ sample analysis is complicated in that the gammas observed often come from their radioactive daughters produced by successive alpha and beta decays. In addition to gamma decay these elements decay by internal conversion, IC, and subsequent 
emission of daughter product $x$-rays. For example, when $235 \mathrm{U}$ alpha decays the result is a radioactive ${ }^{231} \mathrm{Th}$ nucleus. This thorium isotope decays by both gamma emission and internal conversion (IC). Internal conversion results in an electron being ejected; usually from the K-shell; but $\mathrm{L}, \mathrm{M}$ etc. shell conversion are also possible. This ejected electron leaves a hole in the atomic orbit that is filled by the fall of another electron from a higher electron orbital, giving rise to a thorium x-ray spectrum associated with the decay. In addition, x-rays are also produced by gammas interacting (via the photoelectric effect) in the material itself-so called fluorescent $x-$ rays. In the case of a pure uranium sample these will be uranium $x$-rays. Internal conversion processes give rise to characteristic $x$-rays of the daughter product (not the parent) and are not proportional to the amount of material (the amount of thorium in a decaying sample of purified uranium is very small) in the sample. Internally conversion induced $x$-rays are proportional to the number of decays; i.e. each decay has a fractional output of $x$-rays of the daughter product regardless of the parent material present in the sample. This fact makes these x-rays usable for isotopic analysis if the sample has a very low concentration of daughter material (Th). To accurately use these IC $x$-ray peaks requires that the thorium present in very old "natural" uranium samples be removed. $X$-rays induced by the photoelectric effect (fluorsecent $x$-rays) have energies characteristic of the bulk material - being proportional to the mass of material present in the source. The observed x-rays, from both fluorescent and internally converted sources, must originate within a mean free path of the surface to be easily observed.

Branching ratio and gamma, $x$-ray energy data have been published in various places ${ }^{1}, 2^{3}, 4$ for $235 \mathrm{U}$ and ${ }^{238} \mathrm{U}$ and some of their daughter products; but this data is sometimes incomplete, or of inadequate accuracy. The current status of this data are summarized in Appendix A.

Figure 1 shows the main decay scheme for ${ }^{235} \mathrm{U}$ and ${ }^{238} \mathrm{U}$. Pure ${ }^{238} \mathrm{U}$ emits only a $49.55 \mathrm{keV}$ gamma that is so weak as to be almost useless for analysis (see Figure 2.). Fortunately, 238 $\mathrm{U}$ alpha (and beta) decays so that in within a few months it is in equilibrium with the ${ }^{238} \mathrm{U}$ decay and there are gammas from ${ }^{234} \mathrm{Th},{ }^{234} \mathrm{~Pa}$ and ${ }^{234} \mathrm{U}$ available for analysis.(see Appendix $\mathrm{E}$ for a discussion of equilibrium). The small percentage (.0057\%) of natural ${ }^{234} \mathrm{U}$ typically observed is due to the constant decay of $238 \mathrm{U}$. Similarly $235 \mathrm{U}$ relatively quickly decays to equilibrium with its daughters, ${ }^{231} \mathrm{Th}$ and $231 \mathrm{~Pa}$. Samples of uranium that have been enriched or separated can be analyzed for their ${ }^{235} \mathrm{U}$ concentrations by using these daughter product decays in all cases except very fresh (<2 month old) samples. At present the only way to accurately measure "fresh" samples before equilibrium is established is to use mass spectrometry.

Alternately, using high resolution gamma spectrometers, the spectra can be measured and the ${ }^{235} \mathrm{U} /{ }^{238} \mathrm{U}$ ratio determined by finding the peak intensities of neighboring gamma (or $\mathrm{x}$-ray)

1 Firestone, B. F.. ed., "Table of Isotopes", 8th Edition Lawrence Berkeley Laboratory, John Wiley \& Sons, 1996

2 Decay Data of the Transactinium Nuclides, Technical Report 261, IAEA, 1986

${ }^{3}$ Roy, J. C., et. al. Int. J. Appl. Radiation Isotopes, 35, pg 899, 1984

4"Lammer, M. and Schwerer, O. Handbook of Nuclear Data for Safeguards", INDC (NDS) - 248, IAEA, 1991 
peaks from each isotope. By taking intensity ratios on gamma peaks very close to the same energy, the detector efficiency and gamma attenuation differences in the sample will be small and to first order cancel.

When referring to the ${ }^{238} \mathrm{U}$ peaks in the following discussion the assumption is made that the gamma spectrum is in equilibrium with daughters ${ }^{234} \mathrm{Th}(24.1 \mathrm{~d}),{ }^{234} \mathrm{~Pa}(6.70 \mathrm{hr}),. 234 \mathrm{mPa}(1.17$ $\mathrm{min}$.), but not ${ }^{234} \mathrm{U}\left(2.457 \mathrm{E} 5 \mathrm{yr}\right.$.) and its daughters. Similarly, the ${ }^{235} \mathrm{U}$ spectrum is assumed to be in equilibrium with its daughter ${ }^{231} \mathrm{Th}\left(25.52 \mathrm{hr}\right.$.) , but not ${ }^{231} \mathrm{~Pa}(3.276 \mathrm{E} 4 \mathrm{yr}$.) and its daughters.

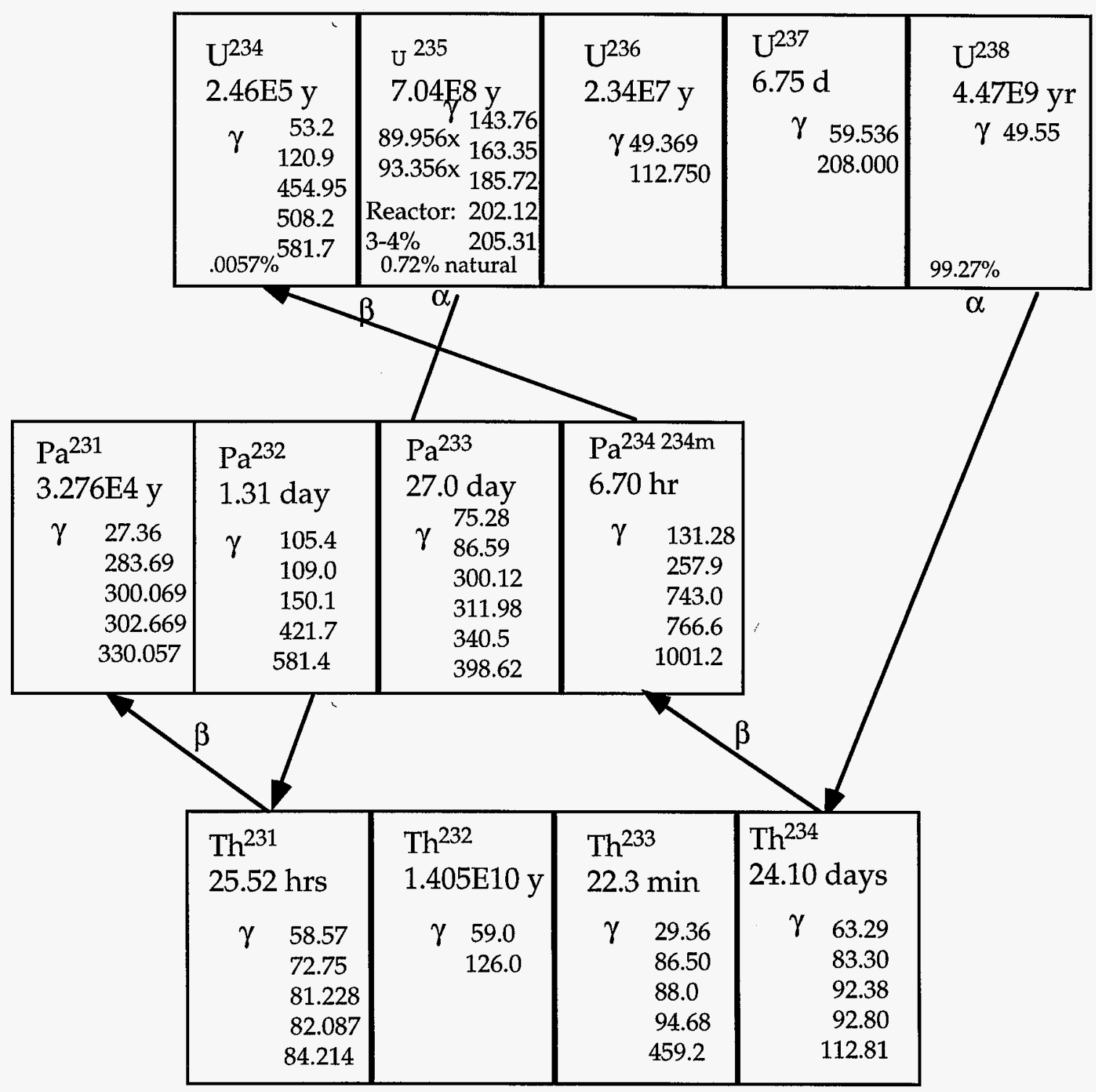

Figure 1. ${ }^{235} \mathrm{U}$ and ${ }^{238} \mathrm{U}$ decay scheme showing their principal daughters, their half-lives and their principal gamma rays. 
The isotopic abundance is related to the observed peak intensities by the following relation:

$$
\mathbf{I}_{1}=\lambda_{1} A_{1} B_{1} \Omega_{1} \varepsilon_{1} \tau_{1} \text { (counts } / \text { sec) }
$$

Where:

$$
\begin{aligned}
& \mathrm{I}_{1}=\text { measured peak intensity of isotope one } \\
& \lambda_{1}=.6932 / \mathrm{T}_{1 / 2}=\text { decay constant of isotope one } \\
& \mathrm{T}_{1 / 2}=\text { material half-life (in seconds) of isotope one } \\
& \mathrm{A}_{1}=\text { Number of atoms of isotope one } \\
& \mathrm{B}_{1}=\text { branching ratio of isotope one } \\
& \Omega_{1}=\text { Fractional solid angle of detector } \\
& \varepsilon_{1}=\text { Gamma counting efficiency of isotope one } \\
& \tau_{1}=\text { Gamma transmission to detector }
\end{aligned}
$$

The isotopic ratio is given by the following equation:

\section{$\mathbf{A}_{1} / \mathbf{A}_{2}=\mathbf{I}_{1} \lambda_{2} \mathbf{B}_{2} \varepsilon_{2} \tau_{2} / \mathbf{I}_{2} \lambda_{1} \mathbf{B}_{1} \varepsilon_{1} \tau_{1}$}

Where:

$\mathrm{A}_{1} / \mathrm{A}_{2}=$ isotopic ratio

$\lambda_{1}=.6932 / \mathrm{T}_{1}=$ decay constant

$\mathrm{T}_{1}=$ material one half-life (in seconds)

$I_{1}$ and $I_{2}=$ measured peak intensities from isotope 1 and 2 respectively

$\mathrm{T}_{1}$ and $\mathrm{T}_{2}=$ half lives, in the same time units, of isotope 1 and 2 respectively

$\varepsilon_{1}$ and $\varepsilon_{2}=$ gamma counting efficiencies of isotope 1 and 2 respectively

$B_{1}$ and $B_{2}=$ branching ratios for characteristic gamma rays of isotope 1 and 2 respectively

Analysis is greatly simplified by the following observations:

$\varepsilon_{2} \tau_{2} / \varepsilon_{1} \tau_{1} \approx 1$ if the two gammas are close to the same energy

$\Omega_{1}=\Omega_{2}$ The fractional solid angle of detector is the same for both gammas and cancels out.

$\lambda_{1}$ and $\lambda_{2}$ are known from the previously measured half lives.

$B_{1}$ and $B_{2}$ are known from the previously measured branching ratios

$I_{1}$ and $I_{2}$ have to be determined extremely accurately to get precise isotopic ratios. 
The analysis proceeds on the assumptions that the solid angle terms cancel out and the half-lives and branching ratios of the respective gamma rays and $x$-rays can be determined. The efficiencies for detecting gamma rays are harder to determine; involving the intrinsic detector efficiencies and the overall detector and counting geometry used to obtain the data. Gamma and x-ray transmissions are nearly equal for energies close to each other. Fortunately, for gammas and $x-$ rays close in energy the ratio of these terms, $\varepsilon_{2} \tau_{2} / \varepsilon_{1} \tau_{1} \approx 1$. Approximate detector efficiencies and gamma transmission corrections are used to make first order corrections to this ratio. The accuracy of determining the isotopic ratio, $\mathrm{A}_{1} / \mathrm{A}_{2}$, is largely determined by the accuracy of determining the respective peak intensities, $\mathrm{I}_{1} / \mathrm{I}_{2}$. The $\mathrm{U} 235$ code determines these peak intensities as accurately as possible and then applies the second order corrections for efficiency and transmission differences between the ratioed peaks to get as accurate an answer as possible.

A literature survey of ${ }^{235} \mathrm{U}$ and ${ }^{238} \mathrm{U}$ gammas and their daughter products found a number of peak groupings that could potentially provide information on isotopic ratios. These are listed in Appendix A. The survey also found that the state of information on the branching ratios and energies of ${ }^{235} \mathrm{U}$ and ${ }^{238} \mathrm{U}$ and their daughter products gammas (and $\mathrm{x}$-rays) were of mixed quality.

\section{The ${ }^{235} \mathrm{U}$ Analysis Code-U235}

The ${ }^{235} \mathrm{U}$ Analysis Code- $-\mathrm{U} 235$ was written to accomplish three main goals: first develop a tool that can accurately determine uranium isotopic ratios; second extend the applicability of the code to very low ${ }^{235} \mathrm{U}$ concentrations (depleted sources) and third to very high $235 \mathrm{U}$ concentration (enriched) sources. Presently the code works for uranium samples that are $0.05 \%{ }^{235} \mathrm{U}$ to $95 \%{ }^{235} \mathrm{U}$. Code algorithms have been found that very precisely subtract the "background" signal and fit the observed peak shapes. X-rays were fit with a Voight profile, the shape resulting from the Lorenzian profile emitted by the $x$-rays and the gaussian detector response. Gammas were fitted with a gaussian profile and a low energy exponential tail. (see Figure 5 and 6 for examples of these profiles). Techniques were developed to unfold the complex peak multiplets observed in the spectra using mathematical descriptions of the peak shapes and utilizing Taylor series minimization to fit the observed data as accurately as possible.

There are several potential energy regions in the uranium gamma ray spectra that can be used to calculate isotopic abundance ratios. In this report only gammas (and x-rays) less than $300 \mathrm{keV}$ are considered. This energy region is measured by a "typical" low energy Ge detector set with a gain of $.075 \mathrm{keV} / \mathrm{channel}$ and 4096 channels of data. A number of $235 \mathrm{U}+238 \mathrm{U}$ spectra were available for this detector arrangement, making it a "natural" first place to start analysis. The only serious limitation this energy range imposes is the relative few $238 \mathrm{U}$ (and daughters) peaks less than 300 $\mathrm{keV}$. Fortunately there are two relatively strong ${ }^{238 \mathrm{U} / 234 \mathrm{Th}}$ lines at 92.365 and $92.790 \mathrm{keV}$ and a relatively strong IC $x$-ray at $93.356 \mathrm{keV} 235 \mathrm{U} / \mathrm{Th}-\mathrm{k} \alpha 1$. (See Appendix A) Higher energy analysis suffers from the opposite problem, there are very few useful ${ }^{235} \mathrm{U}$ peaks above $205 \mathrm{keV}$. One of the disadvantages of using gammas in the 80 to $300 \mathrm{keV}$ range is their limited transmission through " thick" material. This restricts the applicability of the analysis procedures to homogenous sources or "thin" heterogeneous uranium sources. 

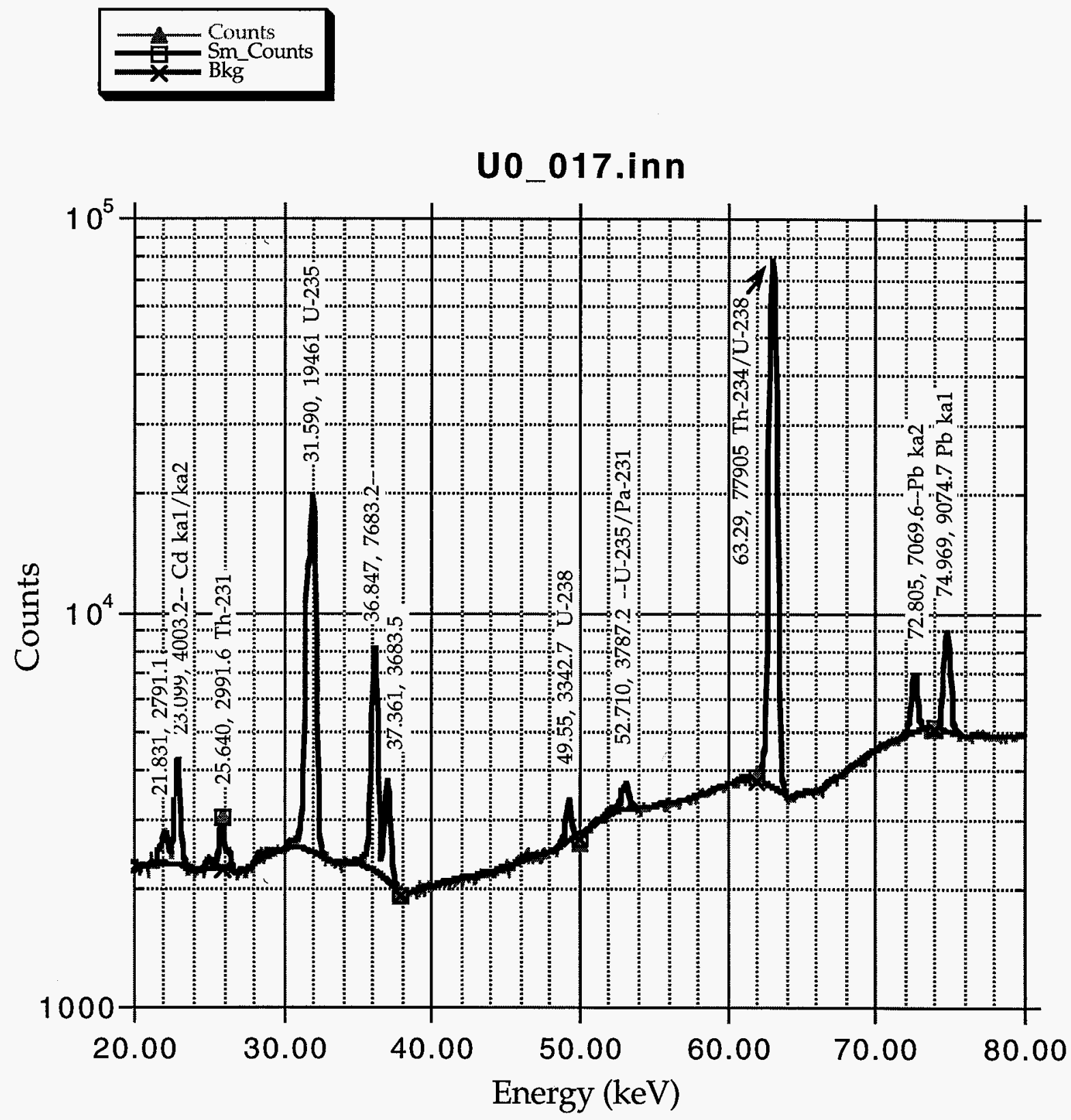

Figure 2. shows a plot of a $99.983 \%{ }^{238} \mathrm{U}$ spectrum from $20-80 \mathrm{keV}$. Clearly shown is the only gamma directly associated with the ${ }^{238} \mathrm{U}$ decay--the $49.55 \mathrm{keV}$ peak. The strongest line in this region is the $238 \mathrm{U}->234$ Th daughter line at $63.29 \mathrm{keV}$. The first number on the peak labels above shows their energy, the second number their approximate peak counts and the third their origin. 

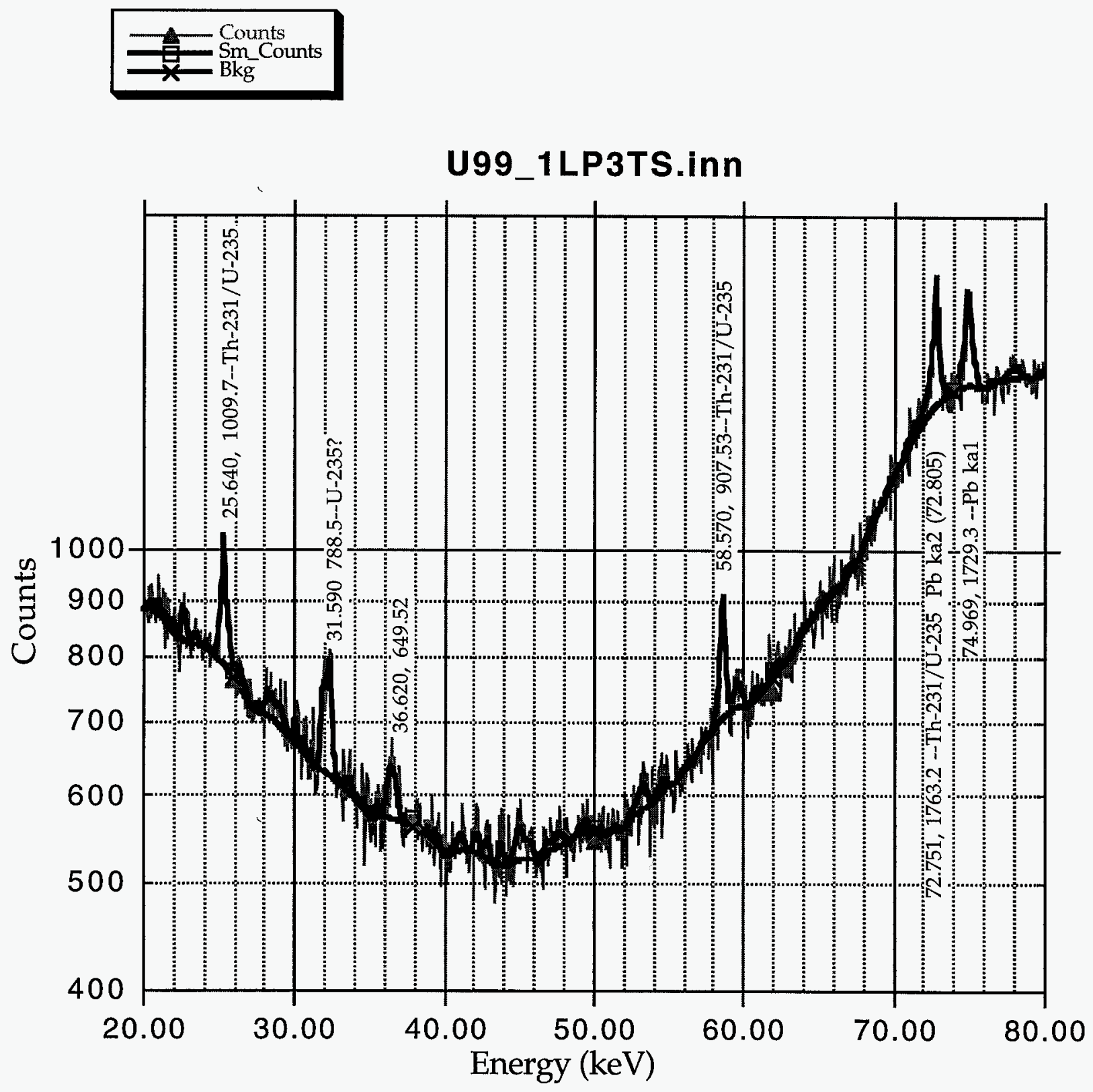

Figure 3. Shows the spectrum from a $99.1 \%$ sample of $235 \mathrm{U}$. It is considerably different than a ${ }^{238} \mathrm{U}$ spectrum shown above. There are no strong lines from ${ }^{235} \mathrm{U}$ or its daughters in this region. The lead $k \alpha 1$ and $k \alpha 2 x$-ray lines are a "typical" spectral contaminate resulting from fluorescent $x$-rays in the collimation etc. 


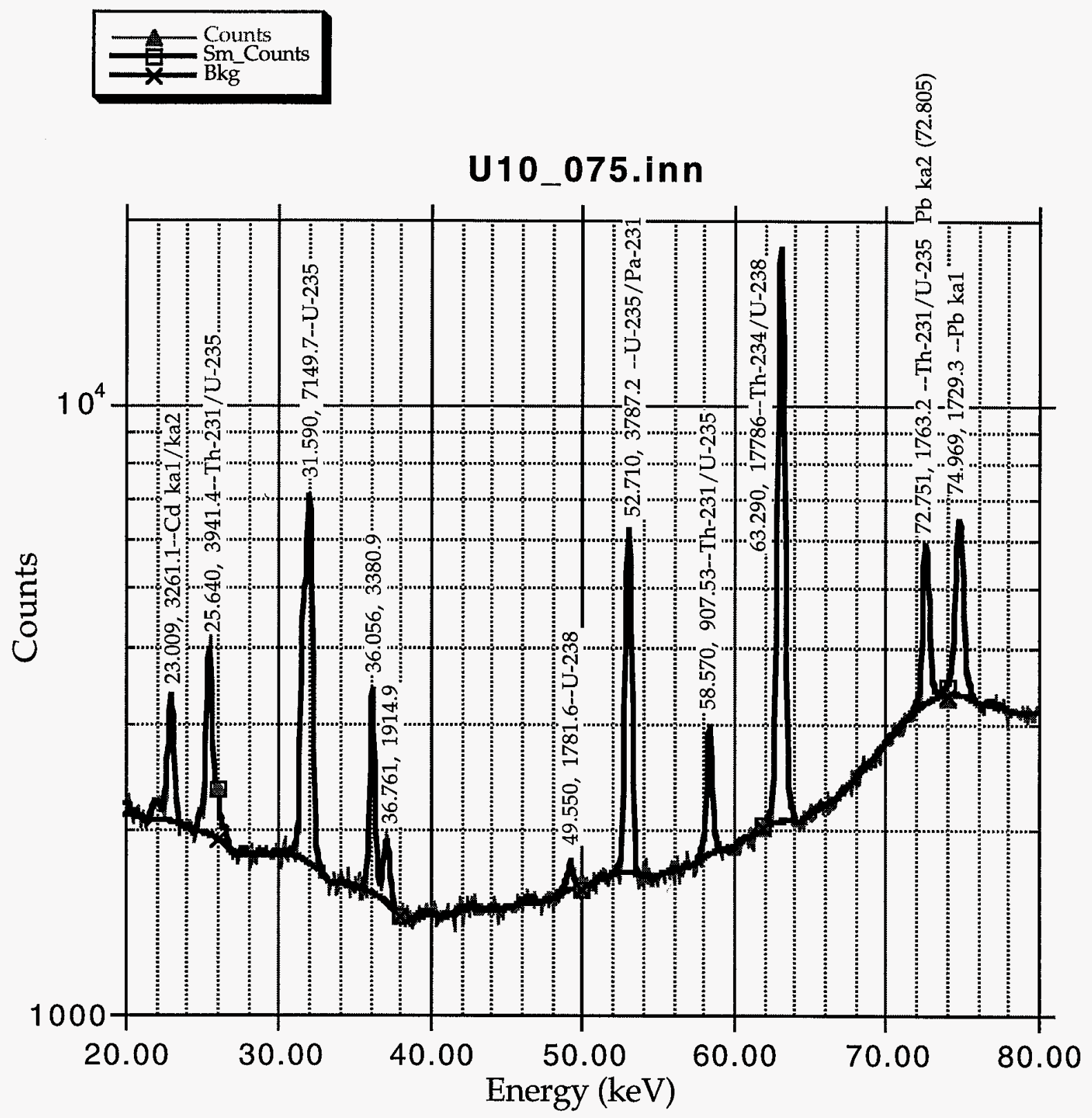

Figure 4.. Plot shows a $10.075 \% 235 \mathrm{U}, 90.0 \% 238 \mathrm{U}$ spectrum from $20-80 \mathrm{keV}$. In this region is shown the only pure $238 \mathrm{U}$ peak at $49.55 \mathrm{keV}$. 
The lowest energy range of "practical" use is the $81-85 \mathrm{keV}$ region. It contains peaks due to ${ }^{235} \mathrm{U}$ $(81.228,82.087$, and $84.214 \mathrm{keV})$ as well as a $83.300 \mathrm{keV}$ peak due to ${ }^{238 \mathrm{U} /}{ }^{234} \mathrm{Th}$ decay. Figure 5. shows the spectrum of a $10.075 \% 235 \mathrm{U}$ sample. Even though the lead $\mathrm{x}$-rays are weak they are a typical "contaminant" to spectra in this region and have to be accounted for accurate peak intensity determinations. The $83.30{ }^{238} \mathrm{U} /{ }^{234} \mathrm{Th}$ peak is quite weak making its accurate determination difficult.

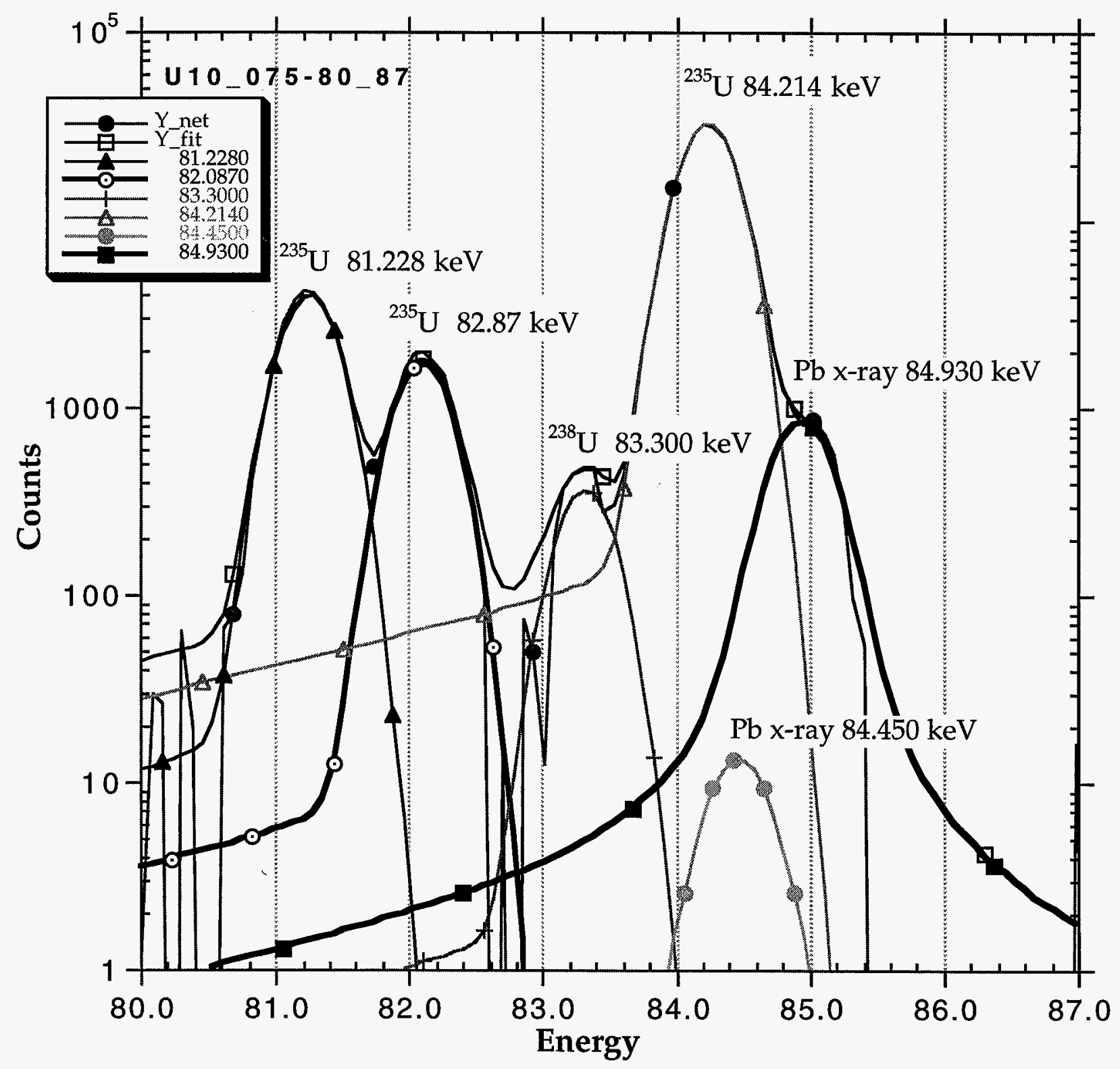

Figure 5. The net (minus background) uranium spectrum (10.075\% $235 \mathrm{U})$ from 80 to $87 \mathrm{keV}$. As can be seen the ${ }^{238} \mathrm{U} /{ }^{234} \mathrm{Th} 83.300$ peak is quite weak, making good peak intensity measurements difficult for this sample and/or lower concentrations of ${ }^{238} \mathrm{U}$. 
This region has three peaks due to $238 \mathrm{U}$, a number of ${ }^{235} \mathrm{U}$ peaks and the two strong $\mathrm{U} k \alpha 1$ and $\mathrm{k} \alpha 2 \mathrm{x}$-ray peaks. The tight clustering of peaks requires careful peak fitting and analysis. For most concentrations this is the region of primary interest since the 92.365 and $92.790238 \mathrm{U}$ peaks are very near the $93.356 \mathrm{Th}-\mathrm{k} \alpha 1 / 235 \mathrm{U}$ peak. The Th $\mathrm{k} \alpha 1$ and Th $\mathrm{k} \alpha 2 \mathrm{x}$-ray peaks, due to $235 \mathrm{U}$ decay, bracket the ${ }^{238} \mathrm{U}$ doublet. The ${ }^{238} \mathrm{U} 95.85$ peak is so weak and has so much interference from the $\mathrm{Pa} k \alpha 195.89 \mathrm{keV}$ peak as to be virtually useless as a diagnostic tool. The main limitations on using this energy range are that at both high ${ }^{235} \mathrm{U}$ and low $235 \mathrm{U}$ concentrations the signals of either the ${ }^{238} \mathrm{U}$ peaks or the ${ }^{235} \mathrm{U}$ peaks are too small, respectively, to accurately determine.

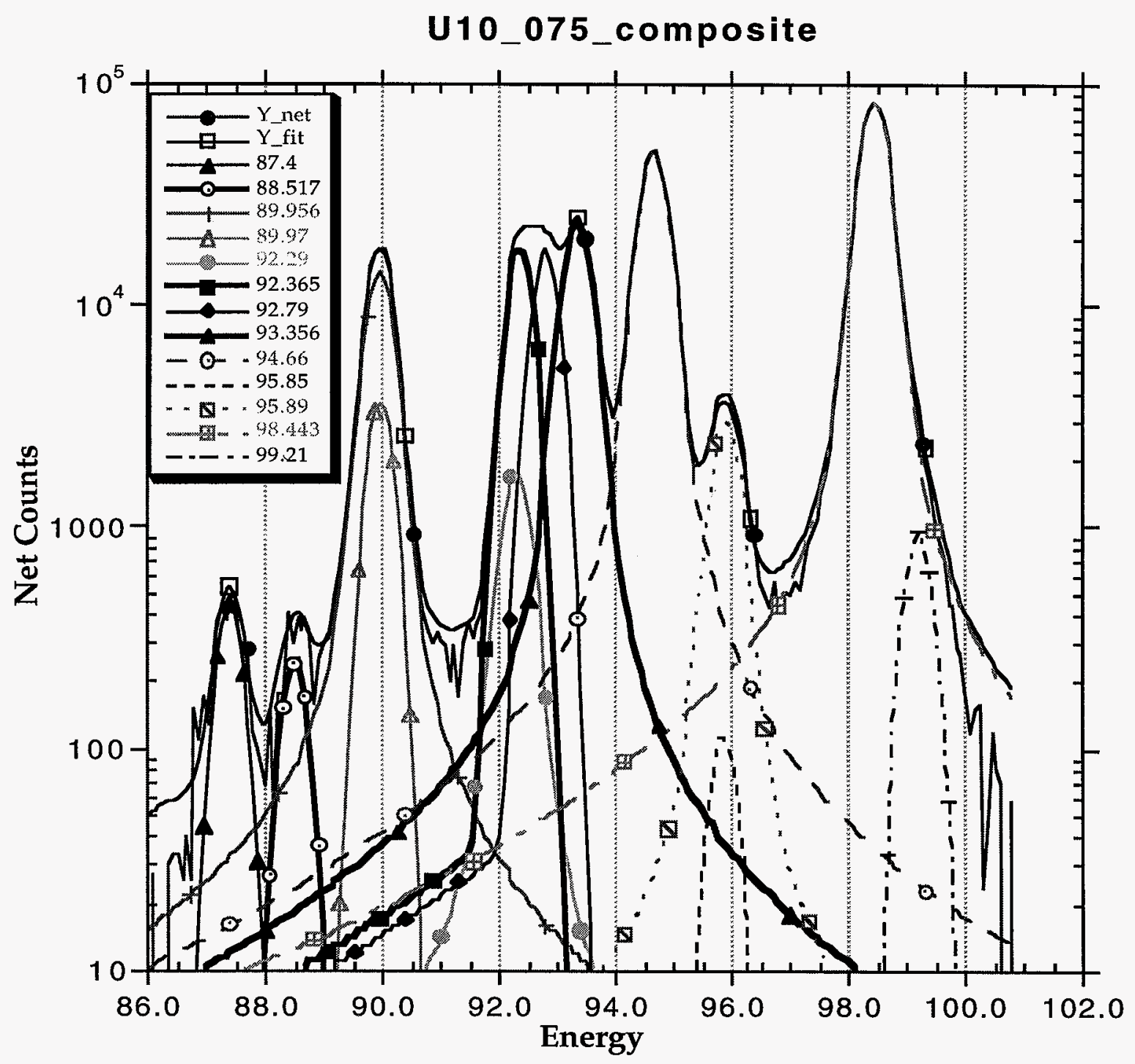

Figure 6a shows all 13 peaks used in fitting the data in the 86-102 keV region. Appendix 1 gives the identification of each of the energies and where they come from. Clearly seen is the gamma ray profile of the ${ }^{238} \mathrm{U}$ peaks and the much broader Voight $x$-ray profile of the ${ }^{235} \mathrm{U} / \mathrm{Th} \mathrm{x}$-ray daughter peaks and the uranium $x$-rays. 


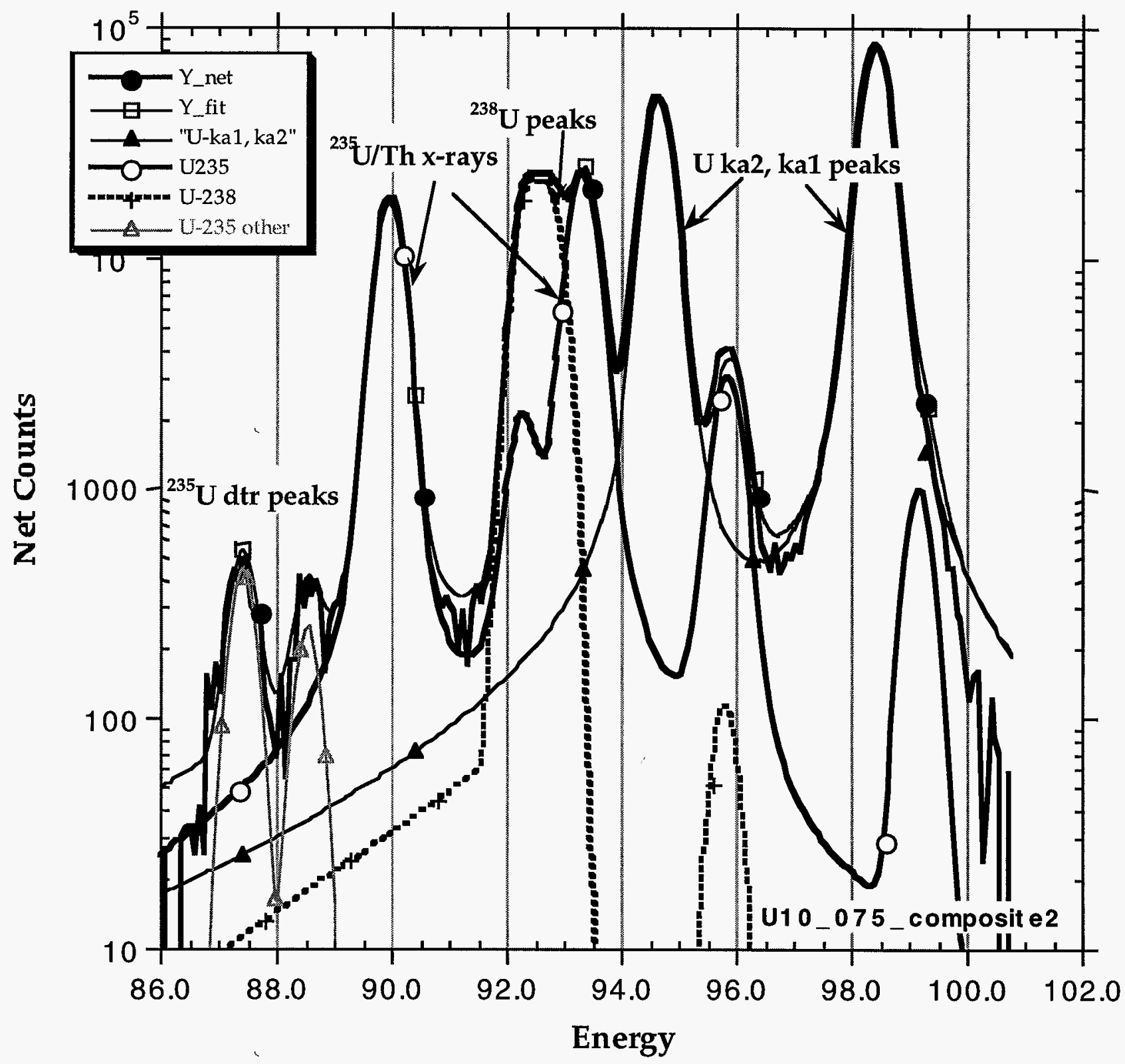

Figure $6 \mathrm{~b}$. The net count spectrum from 86 to $102 \mathrm{keV}$ of a $10.075 \% 235 \mathrm{U}$ sample with the peaks grouped into their respective components. At this ${ }^{235} \mathrm{U}$ concentration the ${ }^{235} \mathrm{U}$ and ${ }^{238} \mathrm{U}$ peaks are approximately equal. The fitting process uses both the protactinium and thorium $x$-rays from the ${ }^{235} \mathrm{U}$ daughters to find the best fit to the combined ${ }^{235} \mathrm{U}$ and ${ }^{238} \mathrm{U}$ spectrum. 


\section{The 100-118 keV Region}

This region is very complex with 21 peaks containing all the $k \beta x$-rays of $U$, Th and Pa plus a $109.2 \mathrm{keV}$ gamma from ${ }^{235} \mathrm{U}$ and a $112.82 \mathrm{keV}$ peak from ${ }^{238} \mathrm{U}$. The large number of peaks and the overlap of peaks due to the wide Voight profile of the x-ray signals makes extracting useful peak ratios difficult. The Th and $\mathrm{Pa}$ x-ray peaks are tied to the ${ }^{235} \mathrm{U}$ decay and might give a useful data if good branching ratios were available-unfortunately they are not. Figure 7 . shows the different $x$-ray multiplets in this region (each the sum of six x-ray peaks) and the two gamma rays. This energy region is not used in the analysis due to the difficult nature of the signals and the "poor" information available on branching ratios.

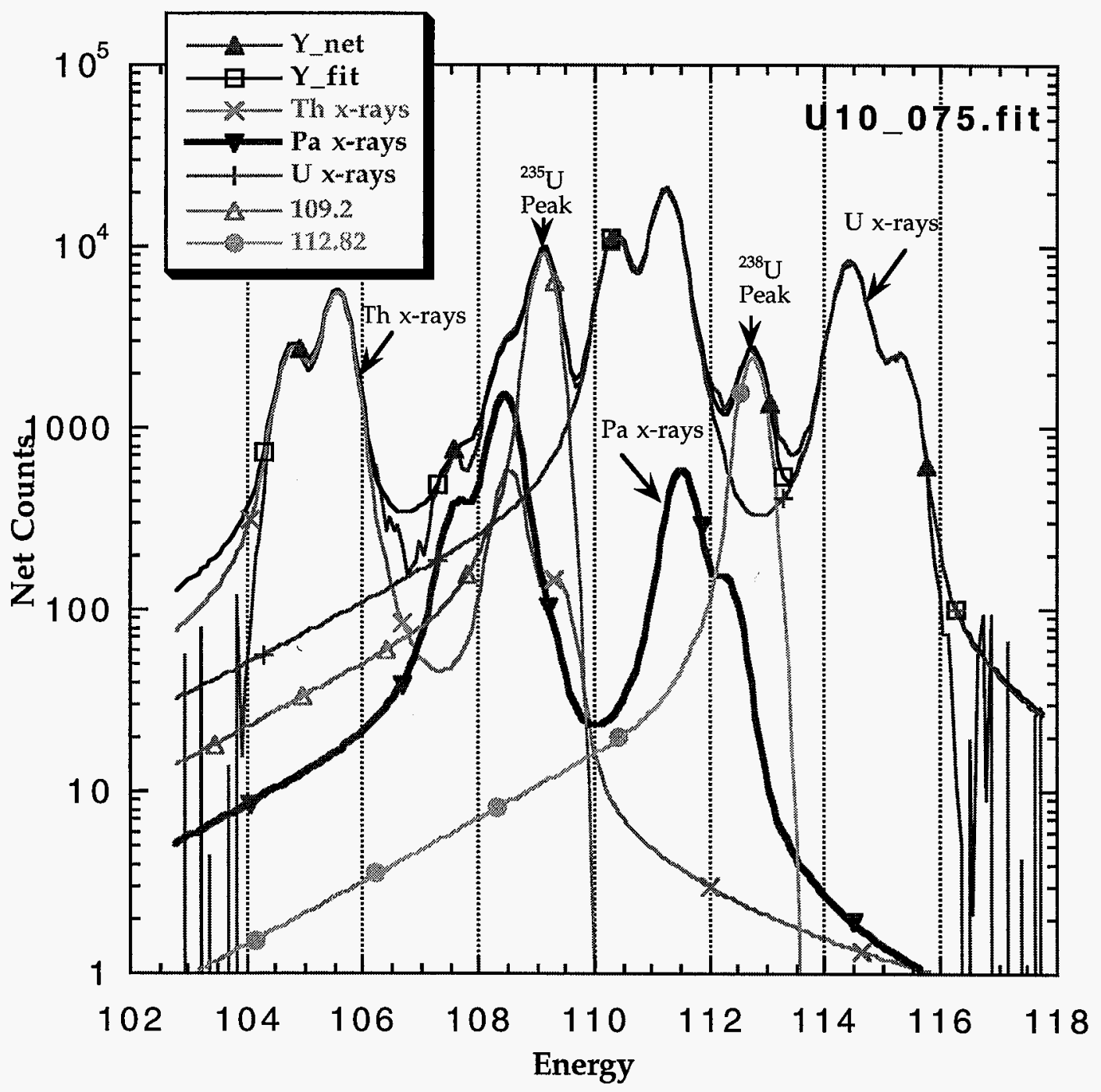

Figure 7. The net count spectrum from 102 to $118 \mathrm{keV}$ of a $10.075 \%$ 235U sample. In this energy range are 21 peaks, mostly thorium, protactinium and uranium $\mathrm{k} \beta \mathrm{x}$-rays. 


\section{The 118-180 keV Region}

The $118-180 \mathrm{keV}$ region has relatively few peaks. The usually clean $120.90 \mathrm{keV}$ peak of ${ }^{234} \mathrm{U}$ is useful for obtaining an estimate of that isotope. This peak suffers in that it is usually weak (sometimes too weak to analyze), giving poor statistic answers and there are no near by peaks to ratio it to. For good accuracy the $120.90 \mathrm{keV}$ peak intensity needs to be corrected for efficiency and gamma transmission.

There are usually no $238 \mathrm{U} /$ daughter peaks of sufficient intensity to be of interest in this region. The only exception is for depleted uranium spectra where the normally weak $131.300 \mathrm{keV}$ $238 \mathrm{U} / 234 \mathrm{~Pa}$ peak is enhanced and the $143.760 \mathrm{keV}{ }^{235} \mathrm{U}$ peak is one of the cleanest ${ }^{235} \mathrm{U}$ peak available (see Figure 8b). Trying to dig the $93.35 \mathrm{keV} 235 \mathrm{U} / \mathrm{Th} \mathrm{x}$-ray peak out of the $82-102$ spectral regions is very inaccurate at very low $235 \mathrm{U}$ concentrations and these isolated ${ }^{235} \mathrm{U}$ and $238 \mathrm{U} /$ daughter peaks in the $118-180 \mathrm{keV}$ region can be more accurately analyzed. The 143.76 and $163.33 \mathrm{keV} 235 \mathrm{U}$ peaks are also potentially useful for establishing the average material thickness in the sample by analyzing their relative intensities. Both of these techniques are utilized in the $\mathrm{U} 235$ code for low ${ }^{235} \mathrm{U}$ concentrations and transmission corrections.

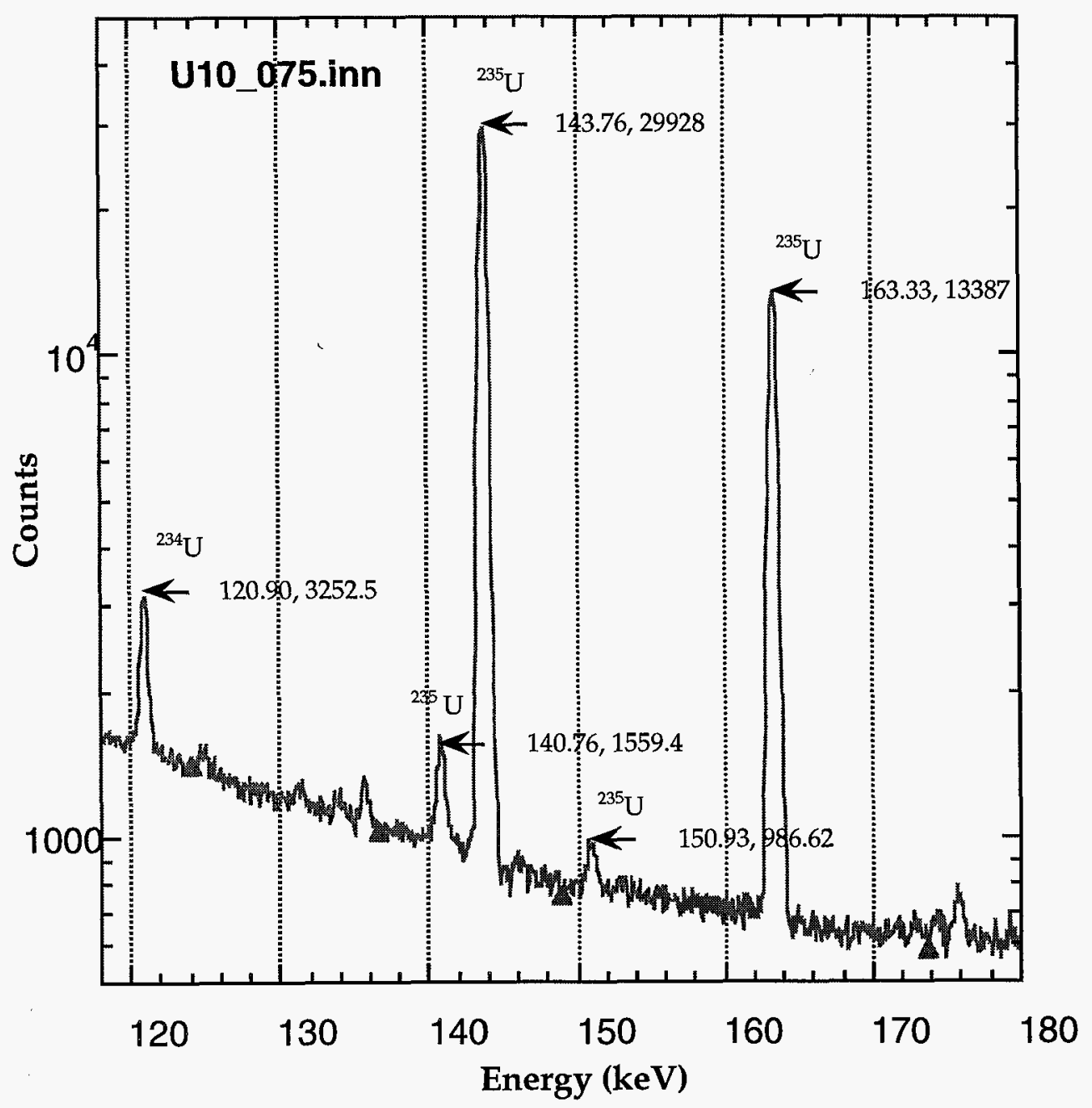

Figure 8a. The gamma spectrum from 118 to $180 \mathrm{keV}$ of a $10.075 \% 235 \mathrm{U}$ sample. Peaks are rather sparse in this region with usable ${ }^{238} \mathrm{U}$ peaks mainly showing up at low ${ }^{235} \mathrm{U}$ concentrations. The 
${ }^{234} \mathrm{U}$ peak at $120.90 \mathrm{keV}$ is usually quite weak but can usually be analyzed because of its isolation. Lack of good statistics on this peak may limit its accuracy.

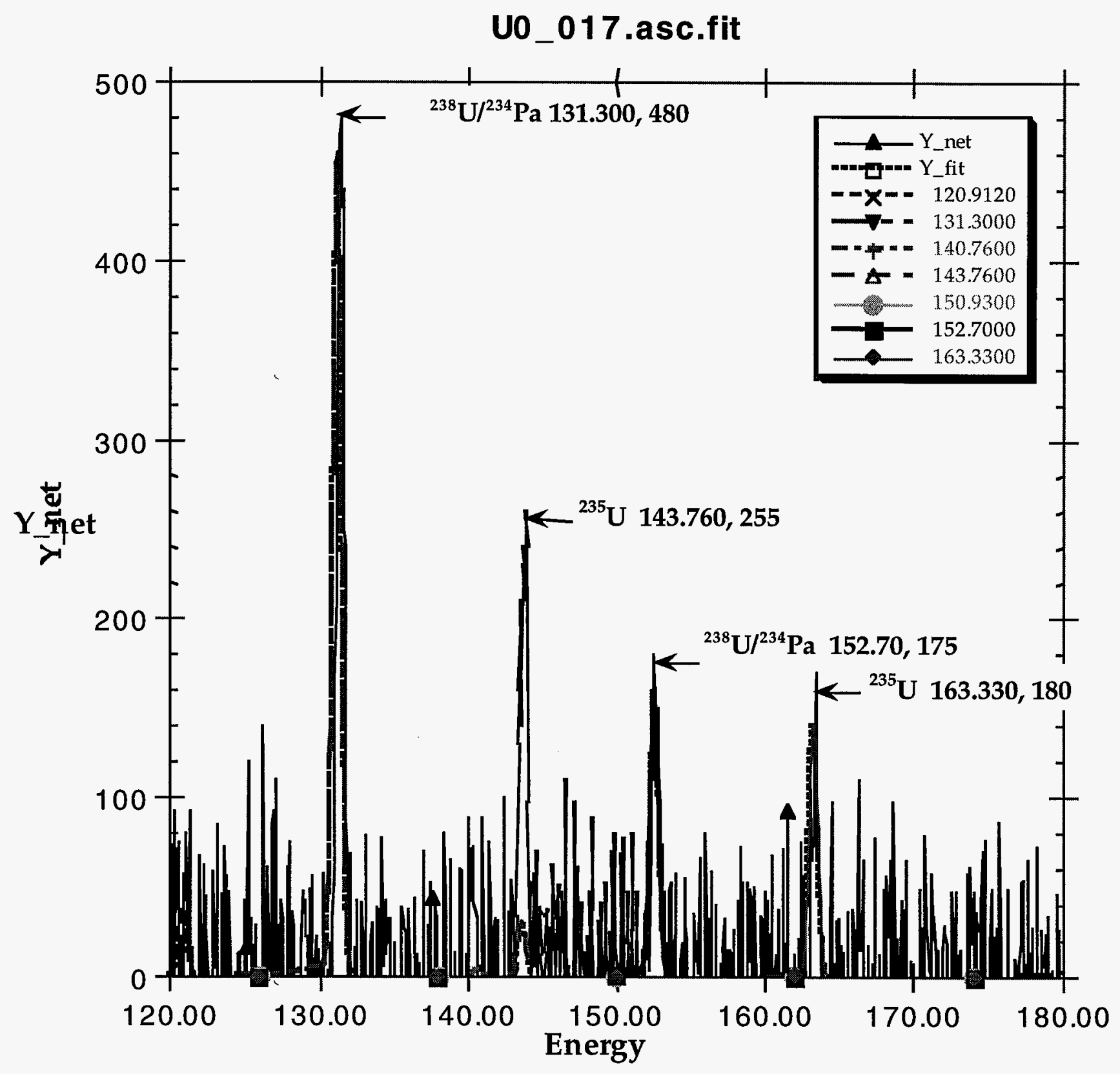

Figure $8 \mathrm{~b}$. showing the same $120-180 \mathrm{keV}$ range for a 0.017 percent $235 \mathrm{U}$ sample. this shows the ${ }^{238} \mathrm{U}$ peaks are enhanced; but the low count rate makes getting decent statistics for analysis very time consuming. The ${ }^{234} \mathrm{U} 120.90 \mathrm{keV}$ peak is normally too weak to analyze at low ${ }^{235} \mathrm{U}$ concentrations. 


\section{The 180-210 keV Region}

The $180-210 \mathrm{keV}$ region has several prominent $235 \mathrm{U}$ peaks including the most intense $235 \mathrm{U}$ peak at $185.715 \mathrm{keV}$. This peak, in conjunction with the $98.443 \mathrm{keV}$ uranium $\mathrm{x}$-ray peak, is used to determine a more accurate gain and zero for the spectrum and to verify that $235 \mathrm{U}$ is present in the spectrum. There are no easily observable ${ }^{238} \mathrm{U}$ peaks in this region. The only major uncertainty here is the $185.712 \mathrm{keV}$ peak which has several other weak peaks around it that must be corrected for to get a good $185.715 \mathrm{keV}$ peak intensity. One of the significant variations observed in this region is the $185.715 \mathrm{keV}$ peak height to $188 \mathrm{keV}$ background ratio. This ratio is found to vary from about 1000 at $90 \%$ enrichment to 1 at $.02 \%$ enrichment. This change is attributed to the high energy gammas in $238 \mathrm{U}$ decay and the contribution they make to the Compton continuum in this energy region. Further investigation is needed to see if these ratios are a function of sample, and detector type-or a universal characteristic of uranium spectra. This ratio is of potential usefulness in establishing a quick estimate of the $235 \mathrm{U}$ enrichment. A spectrum with a high 185.712 to $188 \mathrm{keV}$ ratio has almost certainly a "high" 235U enrichment. Conversely a weak 185.715 peak with a high Compton continuum has a low $235 \mathrm{U}$ enrichment.

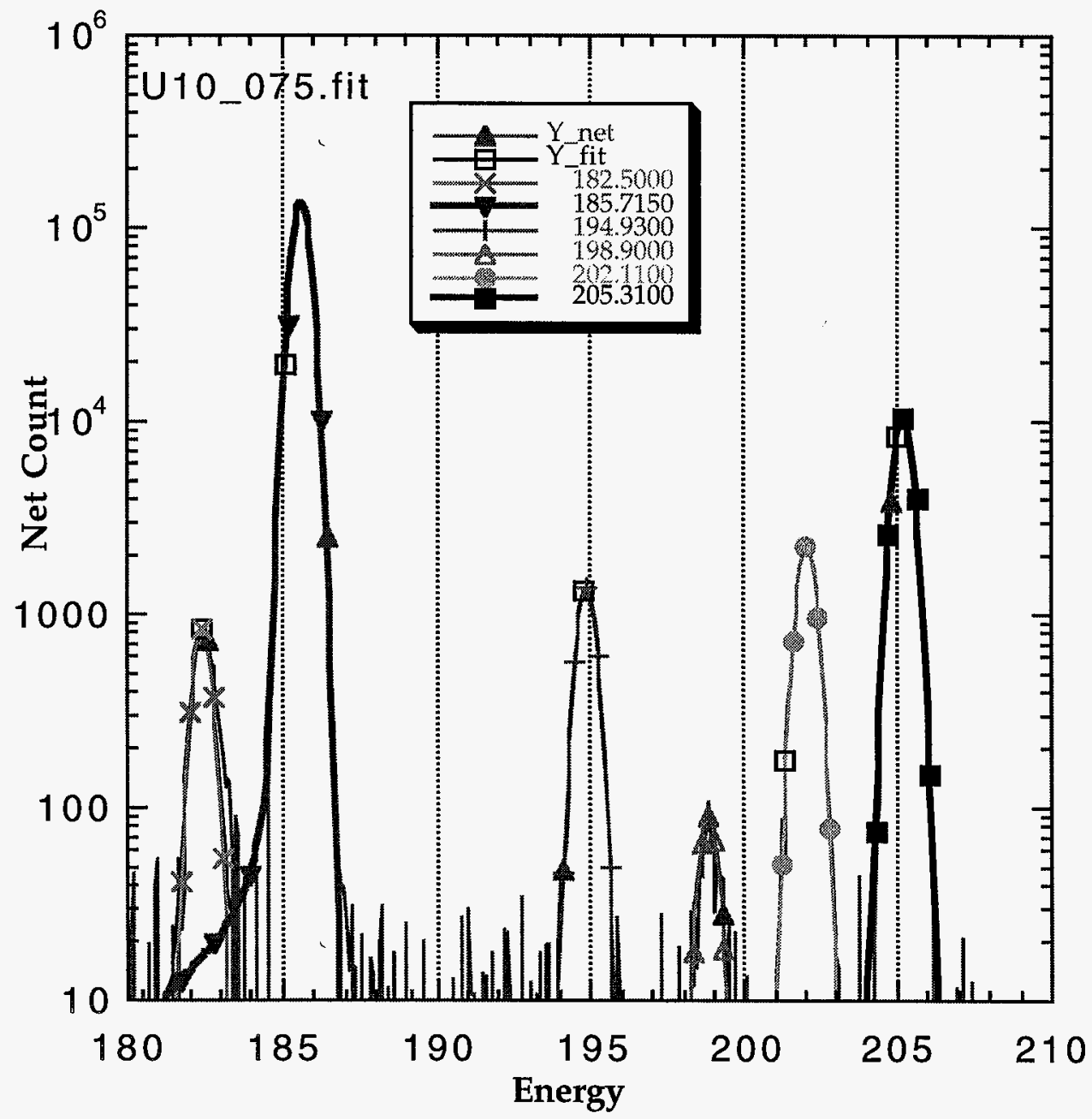

Figure 9. The net count spectrum from 180 to $210 \mathrm{keV}$ of a $10.075 \% 235 \mathrm{U}$ sample. In this region there are typically no ${ }^{238} \mathrm{U}$ peaks intense enough for any peak analysis. 
The 210--300 keV Regiòn

The $210-300 \mathrm{keV}$ region only has one strong $238 \mathrm{U} / 234 \mathrm{mPa}$ peak at $258.2 \mathrm{keV}$. This peak is too weak to be of any great interest. The overall low intensity of this region lowers its utility in analyzing isotopic ratios.

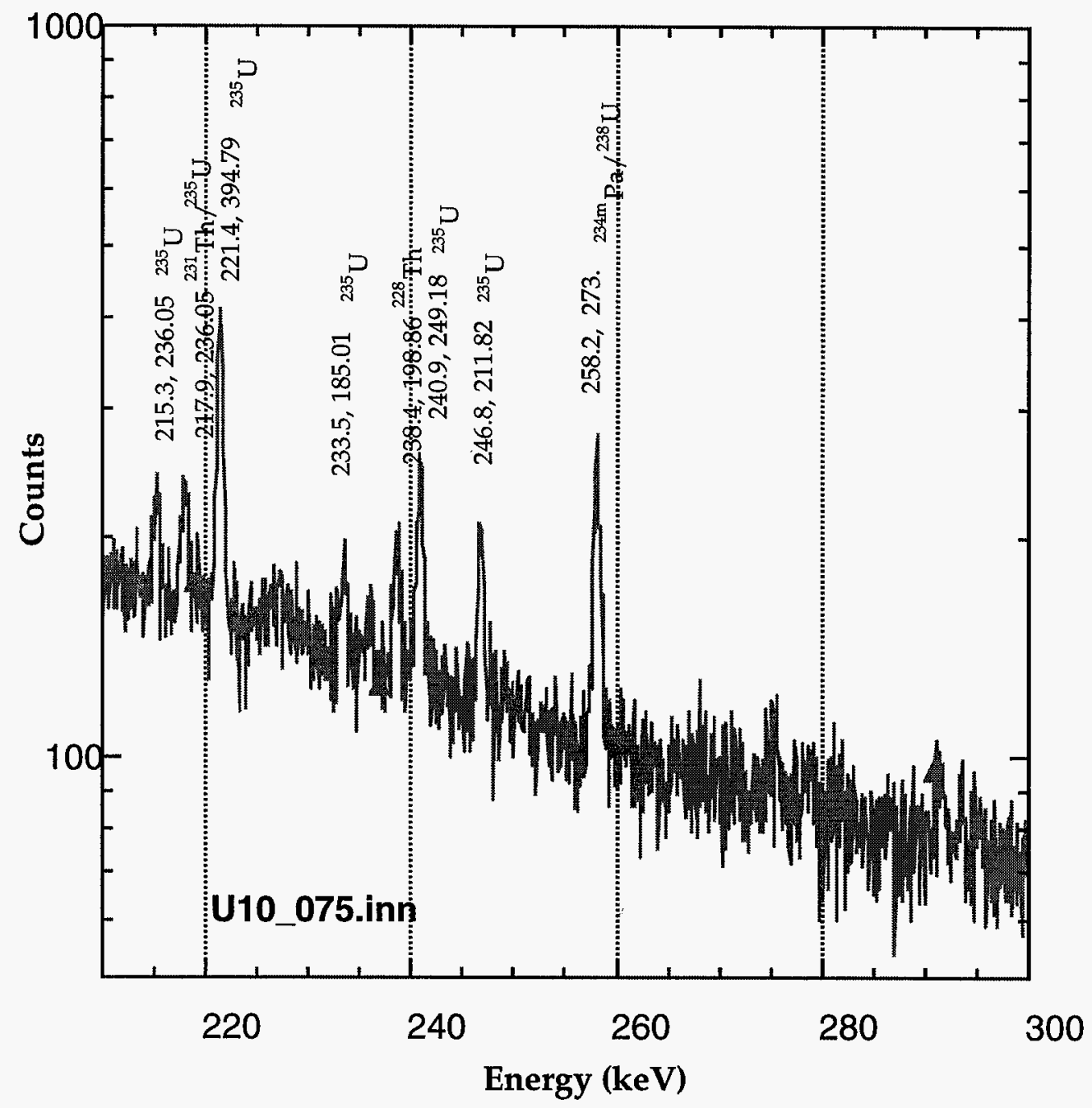

Figure 10. The net count spectrum from 210 to $300 \mathrm{keV}$ of a $10.075 \% 235 \mathrm{U}$ sample. In this region there is only one $238 \mathrm{U}$ peak of interest and a few ${ }^{235} \mathrm{U}$ peaks. 


\section{U235 Calculation Results}

Table 1 shows the results of the $\mathrm{U} 235$ code calculations using the $238 \mathrm{U}$ peaks at 92.29 and $92.7 \mathrm{keV}$ , ratioed with the $93.356 \mathrm{keV}$ Th $\mathrm{k} \alpha 1 / 235 \mathrm{U}$ peak. The first column shows the calculated enrichment on a number of standard (known) sources with the isotopic composition shown in column 2-4. The data in the last column shows the percent difference between the measured and calculated enrichment. As expected the samples that are the most difficult to analyze are where there is either very small $235 \mathrm{U}$ or $238 \mathrm{U}$ signals.

The code has been modified at low $235 \mathrm{U}$ concentrations to use the $131.3 \mathrm{keV} 238 \mathrm{U} / 234 \mathrm{~Pa}$ line and the $235 \mathrm{U}$ lines at 143.76 and $163.33 \mathrm{keV}$ to obtain a more accurate estimate of the $235 \mathrm{U} / 238 \mathrm{U}$ ratio for low ${ }^{235} \mathrm{U}$ concentrations. Normally the $131.3 \mathrm{keV} 238 \mathrm{U} /{ }^{234} \mathrm{~Pa}$ line is too weak to analyze; but at low concentrations the long counting time required to accumulate enough counts combined with the low $235 \mathrm{U}$ emission rate make this line analyzable. It has the additional advantage that there are no competing lines near it; hence even though weak, it is unambiguous to analyze.

Table 1

U235 Code Preliminary Calculation Results

\begin{tabular}{lllll}
$\begin{array}{l}\text { Calc. } \\
\text { U235 }\end{array}$ & $\begin{array}{l}\text { Standard } \\
\text { \% } 235 \mathrm{U}\end{array}$ & $\begin{array}{l}\text { Standard } \\
\% 234 \mathrm{U}\end{array}$ & $\begin{array}{l}\text { Standard } \\
\text { \% 238U }\end{array}$ & $\begin{array}{l}\text { Std-Calc } \\
\% \text { diff. }\end{array}$ \\
\hline 0.0169 & $\mathbf{0 . 0 1 7}$ & 0.001 & 99.982 & $-0.59 \%$ \\
0.5133 & $\mathbf{0 . 4 8 3}$ & 0.005 & 99.512 & $6.27 \%$ \\
1.0126 & $\mathbf{0 . 9 9 1}$ & 0.008 & 99.001 & $2.18 \%$ \\
2.0302 & $\mathbf{2 . 0 1 3}$ & 0.016 & 97.971 & $0.85 \%$ \\
2.9991 & $\mathbf{3 . 0 0 9}$ & 0.031 & 96.960 & $-0.33 \%$ \\
5.0127 & $\mathbf{4 . 9 4 9}$ & 0.041 & 95.010 & $1.29 \%$ \\
10.0806 & $\mathbf{1 0 . 0 7 5}$ & 0.077 & 89.848 & $0.06 \%$ \\
49.1959 & $\mathbf{4 9 . 3 8 0}$ & 0.672 & 49.948 & $-0.37 \%$ \\
75.4537 & $\mathbf{7 5 . 1 3 0}$ & 0.584 & 24.286 & $0.43 \%$ \\
92.982 & $\mathbf{9 3 . 0 7 6}$ & 1.452 & 5.472 & $-0.10 \%$
\end{tabular}

\section{Summary:}

Algorithms are being developed to better subtract backgrounds and improve the high concentration $235 \mathrm{U}$ results. Future plans include expanding the coverage to higher than $300 \mathrm{keV}$ for more complicated spectra and expanding the code to handle mixed Pu and U spectra better. 
Appendix A

\section{Gamma and X-ray Decay of ${ }^{235} U$ and ${ }^{238} U$ and their Daughters}

(data from $49-300 \mathrm{keV}$ )

The gammas energies listed in bold are used with these branching ratios listed in column three to determine ${ }^{235} \mathrm{U} /{ }^{238} \mathrm{U} /{ }^{234} \mathrm{U}$ ratios by the $\mathrm{U} 235$ code. All x-rays listed as IC-decay are internally converted in the isotope and decay with the isotopes decay characteristics-half-life and isotopic composition. All x-rays labeled as fluorescence are caused (nearly completely) by photoelectric absorption in the material and subsequent L-K shell electron decay. These $\mathrm{x}$-rays are characteristic the physical properties of the material and not its isotopic composition. Gammas and x-rays are list by energy. This should allow quicker identification of observed spectra and may help pinpoint potential interference in a given measurement. Only the "strongest" lines are listed, many other gammas in this range are normally too weak to observe. These lines will occur with different intens depending upon the isotopic concentration being observed. The branching ratios listed in column $t$ are the ones presently used at LLNL.

\begin{tabular}{|c|c|c|c|c|c|c|c|}
\hline & E(keV) & $\begin{array}{l}\text { Branch } \\
\text { Ratio- } \\
\text { BR } \times 100\end{array}$ & $\begin{array}{l}g=0 \\
x=-1\end{array}$ & Source & Parent & $\begin{array}{l}\text { URADOSc } \\
\text { Branch Ratio - } \\
\text { BR } \times 100\end{array}$ & $\begin{array}{l}\text { IAEA a } \\
\text { Branch } \\
\text { Ratio } \times 100\end{array}$ \\
\hline \multicolumn{8}{|l|}{ Group-1 } \\
\hline 1 & 49.550 & 0.064 & 0 & U-238 & $\mathrm{U}-238$ & & $0.064 \pm 0.008$ \\
\hline 2 & 53.200 & 0.123 & 0 & U-234 & & & $0.123 \pm 0.002$ \\
\hline 3 & 58.570 & 0.500 & 0 & Th-231 & U-235 & $0.46 \pm 0.060$ & $0.5 \pm 0.05$ \\
\hline 4 & 63.290 & 4.470 & 0 & Th-234 & U-238 & $3.94 \pm 0.010$ & $4.47 \pm 0.88$ \\
\hline 5 & 72.751 & 0.260 & 0 & Th-231 & U-235 & & $0.26 \pm 0.02$ \\
\hline 6 & 72.804 & 27.700 & -1 & $\mathrm{~Pb}-\mathrm{k} \alpha 2$ & fluorescence & & \\
\hline 7 & 73.920 & 0.202 & 0 & $\mathrm{~Pa}-234 \mathrm{~m}$ & $\mathrm{U}-238$ & & \\
\hline 8 & 74.000 & 0.036 & 0 & $\mathrm{~Pa}-234$ & U-238 & & \\
\hline 9 & 74.910 & 0.510 & 0 & U-235 & U-235 & & \\
\hline 10 & 74.969 & 46.200 & -1 & Pb-ka1 & fluorescence & & \\
\hline 11 & 81.228 & 0.850 & 0 & Th-231 & $\mathrm{U}-235$ & & $0.85 \pm 0.03$ \\
\hline 12 & 82.087 & 0.370 & 0 & Th-231 & U-235 & & $0.37 \pm 0.02$ \\
\hline 13 & 83.300 & 0.073 & 0 & Th-234 & U-238 & $0.064 \pm 0.10$ & 0.073 \\
\hline 14 & 84.214 & 6.710 & 0 & Th-231 & U-235 & & $6.71 \pm 0.1$ \\
\hline 15 & 84.450 & 5.580 & -1 & $\mathrm{~Pb}-\mathrm{k} \beta 3$ & fluorescence & & \\
\hline 16 & 84.930 & 10.700 & -1 & $\mathrm{~Pb}-\mathrm{k} \beta 1$ & fluorescence & & \\
\hline 17 & 87.300 & 3.910 & -1 & $\mathrm{~Pb}-\mathrm{k} \beta 2$ & fluorescence & & \\
\hline Group-2 & $\mathrm{E}(\mathrm{keV})$ & $B R \times 100$ & $g=0, x=1$ & Source & Parent & URADOS & IAEA \\
\hline 1 & 87.700 & 0.050 & 0 & Pa-231 & Th-231/U-235 & & \\
\hline 2 & 88.500 & 0.030 & 0 & Th-227 & $\mathrm{U}-235$ & & \\
\hline 3 & 89.956 & 3.360 & -1 & Th $k \alpha 2$ & U-235 IC-decay & $3.17 \pm 0.08$ & $3.4 \pm 0.8$ \\
\hline 4 & 89.970 & 0.742 & 0 & Th-231 & U-235 & $0.97 \pm 0.05$ & \\
\hline 5 & 92.290 & 0.470 & -1 & $\mathrm{~Pa} k \alpha 2$ & U-235 IC-decay & $0.451 \pm 0.036$ & $0.39 \pm 0.03$ \\
\hline 6 & 92.365 & 2.600 & 0 & Th-234 & U-238 & $2.52 \pm 0.06$ & $2.60 \pm 0.53$ \\
\hline 7 & 92.790 & 2.560 & 0 & Th-234 & U-238 & $2.50 \pm 0.06$ & $2.56 \pm 0.52$ \\
\hline 8 & 93.356 & 5.500 & -1 & Th $k \alpha 1$ & U-235 IC-decay & $5.22 \pm 0.14$ & $5.6 \pm 1.3$ \\
\hline 9 & 94.660 & $9.161 t+$ & -1 & $\mathrm{U} \mathrm{k} \alpha 2$ & fluorescence & 61.2 (norm) & $28.2 \pm 0.6$ \\
\hline
\end{tabular}




$\begin{array}{lcccllll}10 & 94.700 & 0.0321 & & \text { Pa-234 } & \text { U-238 } & & \\ 11 & 95.850 & \mathbf{0 . 0 0 2 4} & 0 & \text { Th-234 } & \text { U-238 } & & \\ 12 & 95.860 & 0.880 & -1 & \text { Pa k } \alpha 1 & \text { U-235 IC-decay } & 0.776 \pm 0.043 & 0.63 \pm 0.05 \\ 13 & 98.443 & 14.800+t & -1 & \text { U k } \alpha 1 & \text { fluorescence } & 100.0 \text { (norm) } & 45.1 \pm 0.9 \\ 14 & 99.270 & 0.400 & 0 & \text { Th-231 } & \text { U-235 } & 0.14 \pm .03 & \end{array}$

\begin{tabular}{|c|c|c|c|c|c|}
\hline Group-3 & $\mathrm{E}(\mathrm{keV})$ & BR $\times 100$ & $g=0, x=1$ & Source & Parent \\
\hline 1 & 102.270 & 0.400 & 0 & Th-231 & $U-235$ \\
\hline 2 & 104.819 & 0.137 & -1 & Th $\mathrm{k} \beta 3$ & IC-decay \\
\hline 3 & 105.604 & 0.262 & -1 & Th k $\beta 1$ & IC-decay \\
\hline 4 & 106.239 & 0.009 & -1 & Th k $\beta 5$ & IC-decay \\
\hline 5 & 107.595 & 0.022 & -1 & Pa k $\beta 3$ & IC-decay \\
\hline 6 & 108.422 & 0.042 & -1 & $\mathrm{~Pa} \mathrm{k} \beta 1$ & IC-decay \\
\hline 7 & 108.582 & 0.100 & -1 & Th $k \beta 2$ & IC-decay \\
\hline 8 & 108.955 & 0.003 & -1 & Th $k \beta 4$ & IC-decay \\
\hline 9 & 109.072 & 0.002 & -1 & Pa $k \beta 5$ & IC-decay \\
\hline 10 & 109.160 & 1.540 & 0 & $\mathrm{U}-235$ & $\mathrm{U}-235$ \\
\hline 11 & 109.442 & 0.022 & -1 & Th KO2_3 & IC-decay \\
\hline 12 & 110.480 & 0.555 & -1 & $\mathrm{U} \mathrm{k} \beta 3$ & fluorescence \\
\hline 13 & 110.500 & .0043 & -1 & $\mathrm{U}-238$ & $U-238$ \\
\hline 14 & 111.350 & 1.000 & -1 & $\mathrm{U} \mathrm{k} \beta 1$ & fluorescence \\
\hline 15 & 111.486 & 0.017 & -1 & $\operatorname{Pa~} k \beta 2$ & IC-decay \\
\hline 16 & 111.870 & 0.001 & -1 & Pa k $\beta 4$ & IC-decay \\
\hline 17 & 111.964 & 0.037 & -1 & $\mathrm{U} k \beta 5$ & fluorescence \\
\hline 18 & 112.380 & 0.004 & -1 & $\mathrm{~Pa} \mathrm{KO} 2 \_3$ & IC-decay \\
\hline 19 & 112.820 & 0.040 & 0 & Th-234 & U-238 \\
\hline 20 & 114.540 & 0.388 & -1 & $\mathrm{U} k \beta 2$ & fluorescence \\
\hline 21 & 114.844 & 0.011 & -1 & $\mathrm{U} k \beta 4$ & fluorescence \\
\hline 22 & 114.900 & 0.0064 & 0 & $\mathrm{~Pa}-234 \mathrm{~m}$ & U-238 \\
\hline 23 & 115.377 & 0.089 & -1 & U KO23 & fluorescence \\
\hline
\end{tabular}

URADOS IAEA

$0.40 \pm 0.02$

$1.54 \pm 0.05$

$0.256 \pm 0.054$

\begin{tabular}{|c|c|c|c|c|c|c|c|c|}
\hline \multirow[t]{11}{*}{ Group-4 } & & $\mathrm{E}(\mathrm{keV})$ & BR $\times 100$ & $g=0, x=1$ & Source & Parent & \multirow{2}{*}{$\begin{array}{l}\text { URADOS } \\
0.041 \pm 0.006\end{array}$} & \multirow{2}{*}{$\begin{array}{l}\text { IAEA } \\
0.0342 \pm 0.0005\end{array}$} \\
\hline & 1 & 120.900 & 0.0342 & 0 & U-234 & & & \\
\hline & 2 & 124.914 & 0.0600 & 0 & Th-231 & U-235 & & $0.06 \pm 0.003$ \\
\hline & 3 & 131.300 & 0.0286 & 0 & $\mathrm{~Pa}-234$ & U-238 & & \\
\hline & 4 & 134.030 & 0.0250 & 0 & Th-231 & $\mathrm{U}-235$ & & $0.025 \pm 0.005$ \\
\hline & 5 & 135.664 & 0.0840 & 0 & Th-231 & $\mathrm{U}-235$ & & $0.084 \pm 0.007$ \\
\hline & 6 & 140.760 & 0.2200 & 0 & U-235 & & & $0.22 \pm 0.02$ \\
\hline & 7 & 143.760 & 10.9600 & 0 & U-235 & & $10.95 \pm 0.15$ & $10.96 \pm 0.08$ \\
\hline & 8 & 150.930 & 0.0800 & 0 & U-235 & & & $.08 \pm 0.02^{\mathrm{d}}$ \\
\hline & 9 & 152.700 & 0.0083 & & $\mathrm{~Pa}-234$ & U-238 & & \\
\hline & 10 & 163.330 & 5.0800 & 0 & U-235 & & $5.11 \pm 0.05$ & $5.08 \pm 0.04$ \\
\hline Group-5 & & $\mathrm{E}(\mathrm{keV})$ & BR $\times 100$ & $g=0, x=1$ & Source & Parent & URADOS & IAEA \\
\hline & 1 & 182.610 & 0.3400 & 0 & U-235 & & $0.37 \pm 0.02$ & $0.34 \pm 0.02$ \\
\hline & 2 & 183.500 & 0.0329 & 0 & $\mathrm{U}-235$ & & & .0329 \\
\hline & 3 & 184.800 & 0.2200 & 0 & Th-234 & U-238 & & \\
\hline & 4 & 185.715 & 57.2000 & 0 & U-235 & & $57.2 \pm 0.02$ & $57.2 \pm 0.5$ \\
\hline
\end{tabular}




\begin{tabular}{|c|c|c|c|c|c|c|c|}
\hline 5 & 185.900 & 0.0039 & 0 & $\mathrm{~Pa}-234$ & U-238 & & $3.89 \mathrm{E}-3$ \\
\hline 6 & 194.940 & 0.6300 & 0 & U-235 & & & $0.630 \pm 0.01$ \\
\hline 7 & 198.900 & 0.0420 & 0 & U-235 & & & 0.042 \\
\hline 8 & 202.110 & 1.0800 & 0 & U-235 & & & $1.080 \pm 0.02$ \\
\hline 9 & 205.311 & 5.0100 & 0 & U-235 & & & $5.010 \pm 0.05$ \\
\hline Group -6 & $\mathrm{E}(\mathrm{keV})$ & BR x100 & $g=0, x=1$ & Source & Parent & URADOS & IAEA \\
\hline 1 & 215.30 & 0.0288 & 0 & U-235 & & & \\
\hline 2 & 217.94 & 0.0370 & 0 & Th-231 & U-235 & & $0.037 \pm 0.001$ \\
\hline 3 & 221.38 & 0.1200 & 0 & U-235 & & & $0.12 \pm 0.01$ \\
\hline 4 & 226.63 & 0.0059 & 0 & $\mathrm{~Pa}-234$ & U-238 & & \\
\hline 5 & 227.17 & 0.0055 & 0 & $\mathrm{~Pa}-234$ & U-238 & & \\
\hline 6 & 233.50 & 0.0290 & 0 & U-235 & & & \\
\hline 7 & 238.50 & 0.0092 & 0 & Th-231 & U-235 & & \\
\hline 8 & 240.85 & 0.0540 & 0 & U-235 & & & \\
\hline 9 & 246.84 & 0.0530 & 0 & $\mathrm{U}-235$ & & & \\
\hline 10 & 258.20 & 0.0730 & 0 & $\mathrm{~Pa}-234 \mathrm{~m}$ & U-238 & & \\
\hline 11 & 291.63 & 0.0180 & 0 & U-235 & & & \\
\hline 12 & 293.90 & 0.0039 & 0 & $\mathrm{~Pa}-234$ & U-238 & & \\
\hline
\end{tabular}

a. "Handbook of Nuclear Data for Safeguards", INDC (NDS) - 248, IAEA, 1991

b. GAMGEN code LLNL

c. Presented in CEA meeting by DAMPRI-LPRI May 1996

d. "Decay Data of the Transactinium Nuclides", Report \# 261, IAEA, 1986

\section{${ }^{238} \mathrm{U}$ and Daughters- ${ }^{234} \mathrm{~Pa}$ and ${ }^{234} \mathrm{Th}$}

GAMGEN Calculation showing gammas/sec/gram of $238 \mathrm{U}(\mathrm{g} / \mathrm{s} / \mathrm{gm})$ at 5 years since separation and the implied Branching Ratio.(Branching Ratio normalized to $2.60 \%$ at $92.3 \mathrm{keV}$ )

\begin{tabular}{rccccccc}
$\mathbf{E}(\mathbf{k e V})$ & $\mathbf{g} / \mathbf{s} / \mathbf{g m}$ & $\mathbf{g}=\mathbf{0}, \mathbf{x}=\mathbf{1}$ & $\mathbf{B R} \mathbf{x 1 0 0}$ & Source & Parent1 & Emiter2 & Parent2 \\
\hline 62.9 & 2.36 & 0 & 0.0182 & Th-234 & U-238 & & \\
73.9 & 1.36 & 0 & 0.0105 & Pa-234m & U-238 & & \\
74.0 & 5.30 & 0 & 0.0408 & Th-234 & U-238 & & \\
83.3 & 8.71 & 0 & 0.0670 & Th-234 & U-238 & & \\
92.3 & 338.0 & 0 & 2.6000 & Th-234 & U-238 & & \\
92.8 & 335.0 & 0 & 2.5769 & Th-234 & U-238 & & \\
94.7 & 21.6 & 0 & 0.1662 & Pa-234m & U-238 & Pa-234 & U-238 \\
95.9 & 1.62 & 0 & 0.0125 & Th-234 & U-238 & & \\
110.5 & 2.98 & 0 & 0.0229 & U-238 & U-238 & & \\
114.9 & 4.32 & 0 & 0.0332 & Pa-234m & U-238 & Pa-234 & U-238 \\
131.3 & 3.23 & 0 & 0.0248 & Pa-234 & U-238 & & \\
152.7 & 1.08 & 0 & 0.0083 & Pa-234 & U-238 & & \\
184.8 & 1.49 & 0 & 0.0115 & Th-234 & U-238 & & \\
258.2 & 9.02 & 0 & 0.0694 & Pa-234m & U-238 & &
\end{tabular}




\section{Appendix B \\ Uranium and Daughter $\mathrm{X}$-rays*}

\begin{tabular}{ccccccc}
\multicolumn{3}{c}{ Th X-rays } & \multicolumn{3}{c}{ Pa X-rays } \\
E(keV) & $\%$ & E(keV) & $\%$ & E(keV) & $\%$ & U X-rays \\
\hline 93.350 & 45.400 & 95.863 & 45.3 & 98.434 & 45.1 & $\mathrm{k} \alpha 1$ \\
89.957 & 28.100 & 92.282 & 28.1 & 94.654 & 28.2 & $\mathrm{k} \alpha 2$ \\
105.604 & 10.700 & 108.422 & 10.7 & 111.298 & 10.7 & $\mathrm{k} \beta 1$ \\
108.582 & 4.100 & 111.486 & 4.163 & 114.445 & 4.15 & $\mathrm{k} \beta 2$ \\
104.819 & 5.610 & 107.595 & 5.64 & 110.421 & 5.65 & $\mathrm{k} \beta 3$ \\
108.955 & 0.110 & 111.870 & 0.11 & 114.844 & 0.12 & $\mathrm{k} \beta 4$ \\
106.239 & 0.380 & 109.072 & 0.389 & 111.964 & 0.397 & $\mathrm{k} \beta 5$ \\
109.442 & 0.900 & 112.380 & 0.93 & 115.377 & 0.95 & $\mathrm{k} 02 \_3$ \\
\% refers to percent decay per 100 k-shell vacancies & & \\
* Browne, E. and Firestone, R., “Table of Radioactive Isotopes”, LBL, 2986, pg. C-23
\end{tabular}

\section{X-rays associated with Uranium decay-sorted by energy.}

Uranium $\mathrm{x}$-ray fluorescence intensity is set to 1.00 for $\mathrm{U}-\mathrm{k} \alpha 1$ in this comparison. The other branching ratios are derived from the observed decay of $235 \mathrm{U}$. The Pa branching ratios determined from the protactinium fluorescent decay ratios normalized to a 0.042 branching ratio for the $\mathrm{Pa} \mathrm{k} \beta 1$ line at $108.422 \mathrm{keV}$. The thorium branching ratios determined from the Th fluorescent decay ratios normalized to a .503 branching ratio for the Th $\mathrm{k} \alpha 1$ line at $93.350 \mathrm{keV}$. [All data preliminary.]

\begin{tabular}{rrrrll}
\multicolumn{1}{c}{ E(keV) } & \% & Branch Ratio & & & Type x-ray \\
\hline 89.957 & 28.100 & 0.3113 & $\mathbf{T h}$ & $\mathbf{k} \alpha 2$ & IC-decay \\
92.282 & 28.100 & 0.1103 & $\mathbf{P a}$ & $\mathbf{k} \alpha 2$ & IC-decay \\
93.350 & 45.400 & 0.5030 & $\mathbf{T h}$ & $\mathbf{k} \alpha 1$ & IC-decay \\
94.654 & 28.200 & 0.6253 & $\mathbf{U}$ & $\mathbf{k} \alpha 2$ & fluorescence \\
95.863 & 45.300 & 0.1778 & $\mathbf{P a}$ & $\mathbf{k} \alpha 1$ & IC-decay \\
98.434 & 45.100 & 1.0000 & $\mathbf{U}$ & $\mathbf{k} \alpha 1$ & fluorescence \\
104.819 & 5.610 & 0.0622 & $\mathbf{T h}$ & $\mathbf{k} \beta 3$ & IC-decay \\
105.604 & 10.700 & 0.1185 & $\mathbf{T h}$ & $\mathbf{k} \beta 1$ & IC-decay \\
106.239 & 0.380 & 0.0042 & $\mathbf{T h}$ & $\mathbf{k} \beta 5$ & IC-decay \\
107.595 & 5.640 & 0.0221 & $\mathbf{P a}$ & $\mathbf{k} \beta 3$ & IC-decay \\
108.422 & 10.700 & 0.0420 & $\mathbf{P a}$ & $\mathbf{k} \beta 1$ & IC-decay \\
108.582 & 4.100 & 0.0454 & $\mathbf{T h}$ & $\mathbf{k} \beta 2$ & IC-decay \\
108.955 & 0.110 & 0.0012 & $\mathbf{T h}$ & $\mathbf{k} \beta 4$ & IC-decay \\
109.072 & 0.389 & 0.0015 & $\mathbf{P a}$ & $\mathbf{k} \beta 5$ & IC-decay \\
109.442 & 0.900 & 0.0100 & $\mathbf{T h}$ & $\mathbf{k 0 2} \mathbf{3} 3$ & IC-decay \\
110.421 & 5.650 & 0.1253 & $\mathbf{U}$ & $\mathbf{k} \beta 3$ & fluorescence \\
111.298 & 10.700 & 0.2373 & $\mathbf{U}$ & $\mathbf{k} \beta 1$ & fluorescence \\
111.486 & 4.163 & 0.0163 & $\mathbf{P a}$ & $\mathbf{k} \beta 2$ & IC-decay \\
111.870 & 0.110 & 0.0004 & $\mathbf{P a}$ & $\mathbf{k} \beta 4$ & IC-decay \\
& & & & & -21 -
\end{tabular}




$\begin{array}{lllcll}111.964 & 0.397 & 0.0088 & \mathbf{U} & \mathbf{k} \beta 5 & \text { fluorescence } \\ 112.380 & 0.930 & 0.0037 & \mathbf{P a} & \mathbf{k 0 2 \_ 3} & \text { IC-decay } \\ 114.445 & 4.150 & 0.0920 & \mathbf{U} & \mathbf{k} \beta 2 & \text { fluorescence } \\ 114.844 & 0.120 & 0.0027 & \mathbf{U} & \mathbf{k} \beta 4 & \text { fluorescence } \\ 115.377 & 0.950 & 0.0211 & \mathbf{U} & \mathbf{k 0 2 \_ 3} & \text { fluorescence }\end{array}$

\begin{tabular}{|c|c|c|c|c|c|c|c|}
\hline E(keV) & $\begin{array}{l}\text { Th X-rays } \\
\text { measured }^{*}\end{array}$ & $\begin{array}{l}\text { Norm. } \\
\text { meas. }\end{array}$ & $\begin{array}{c}\text { Intensity } \\
\% \\
\end{array}$ & $\begin{array}{c}\text { Scofield } \\
\text { Calculation }\end{array}$ & $\begin{array}{c}\text { Th X-rays } \\
\%\end{array}$ & & $\begin{array}{c}\text { Calc-Meas. } \\
\% \text { diff }\end{array}$ \\
\hline 93.350 & 93.348 & 100 & 45.4 & 100 & 45.40 & $k \alpha 1$ & 0 \\
\hline 89.957 & 89.957 & 61 & 27.694 & 61.9 & 28.10 & $\mathbf{k} \alpha 2$ & 0 \\
\hline 105.604 & 105.606 & 19 & 8.626 & 22.35 & 10.70 & $k \beta 1$ & 2.47 \\
\hline 108.582 & 108.471 & 10 & 4.54 & 8.5601 & 4.10 & $k \beta 2$ & 2.5 \\
\hline 104.819 & 104.822 & & & 11.466 & 5.61 & $k \beta 3$ & 3.53 \\
\hline 108.955 & & & & & 0.11 & $\mathbf{k} \beta 4$ & \\
\hline 106.239 & & & & 0.8247 & 0.38 & $k \beta 5$ & 0.68 \\
\hline 109.442 & & & & & 0.90 & k02_3 & \\
\hline \multicolumn{8}{|c|}{ Pa X-rays } \\
\hline $\mathbf{E}(\mathbf{k e V})$ & & & & & $\%$ & & \\
\hline 95.863 & 95.867 & 100 & 45.3 & 100 & 45.300 & $\mathbf{k} \alpha 1$ & 0 \\
\hline 92.282 & 92.284 & 62 & 28.086 & 62.2 & 28.100 & $\mathbf{k} \alpha 2$ & -0.1 \\
\hline 108.422 & 108.418 & 24 & 10.872 & 22.45 & 10.700 & $\mathbf{k} \beta 1$ & 2.36 \\
\hline 111.486 & & & 0 & 8.6882 & 4.163 & $k \beta 2$ & 2.62 \\
\hline 107.595 & 107.586 & 11 & 4.983 & 11.472 & 5.640 & $k \beta 3$ & 3.86 \\
\hline 111.870 & & & & & 0.110 & $\mathrm{k} \beta 4$ & \\
\hline 109.072 & & & & 0.8441 & 0.389 & $\mathbf{k} \beta 5$ & 0.78 \\
\hline 112.380 & & & & & 0.930 & k02_3 & \\
\hline \multicolumn{8}{|c|}{ U X-rays } \\
\hline $\mathrm{E}(\mathrm{keV})$ & & & & & $\%$ & & \\
\hline 98.434 & 98.435 & & & 100 & 45.100 & $\mathbf{k} \alpha 1$ & 0 \\
\hline 94.654 & 94.656 & & & 62.5 & 28.200 & $\mathbf{k} \alpha 2$ & 0.02 \\
\hline 111.298 & 111.300 & & & 22.6 & 10.700 & $k \beta 1$ & 2.25 \\
\hline 114.445 & & & & 8.7462 & 4.150 & $k \beta 2$ & 2.35 \\
\hline 110.421 & 110.416 & & & 11.549 & 5.650 & $\mathbf{k} \beta 3$ & 3.82 \\
\hline 114.844 & & & & & 0.120 & $\mathrm{k} \beta 4$ & \\
\hline 111.964 & 112.043 & & & 0.8656 & 0.397 & $\mathbf{k} \beta 5$ & 0.77 \\
\hline \multirow[t]{2}{*}{115.377} & & & & & 0.950 & k02_3 & \\
\hline & $\mathbf{k} \alpha 2 / \mathbf{k} \alpha 1$ & $\mathbf{k} \beta 1 / \mathbf{k} \alpha 1$ & $k \beta 3 / k \beta 1$ & $k \beta 5 / k \beta 1$ & & & \\
\hline Th & 0.619 & 0.224 & 0.513 & 0.0369 & & & \\
\hline $\mathbf{P a}$ & 0.622 & 0.225 & 0.512 & 0.0376 & & & \\
\hline $\mathbf{U}$ & 0.625 & 0.226 & 0.511 & 0.0383 & & & \\
\hline
\end{tabular}

Scofield, J. D. "Relativistic Hartree-Slater Values of the K and L X-ray Emission" Atomic Data and Nuclear Data Tables 14, 121-137(1974)

*Barreau, G. et. al., "Z. Phys. A. Atoms and Nuclei" 308, 209-213 (1982) 


\begin{tabular}{|c|c|c|c|c|c|c|c|c|}
\hline & ${ }^{5} \mathrm{U} \mathrm{Da}$ & ughter & 231 & $\begin{array}{r}\mathrm{Al}_{1} \\
\mathrm{~h} \mathrm{Gar}\end{array}$ & $\begin{array}{l}\text { endix } \\
\text { nas, } \mathrm{Pa}\end{array}$ & rays, and & Branching & Ratios \\
\hline E(keV) & $\pm \Delta \mathrm{E}$ & $\begin{array}{c}\text { IAEA } \\
\text { E(keV) }\end{array}$ & $\begin{array}{l}x=- \\
1\end{array}$ & $\begin{array}{l}{ }^{*} \text { Rel. } \\
\text { Int } b\end{array}$ & $\pm \Delta \mathbf{I}$ & Notes: & $\begin{array}{c}\text { Branch Ratio } \\
\text { (IAEA) }\end{array}$ & $\begin{array}{c}\text { Imp. Branch } \\
\text { Ratio }^{\mathbf{a}}\end{array}$ \\
\hline 26.560 & & 25.640 & & 202 & 20 & & 0.146 & 0.135542 \\
\hline 44.100 & 0.3 & & & 0.06 & 0.04 & & & $4.03 \mathrm{E}-05$ \\
\hline 58.470 & 0.05 & 58.570 & & 7.2 & 0.7 & & 0.005 & 0.004831 \\
\hline 63.700 & 0.2 & & & 0.68 & 0.14 & & & 0.000456 \\
\hline 72.660 & 0.06 & 72.751 & & 4 & 0.4 & & 0.0026 & 0.002684 \\
\hline 73.000 & 0.1 & & & 0.1 & 0.04 & & & $6.71 \mathrm{E}-05$ \\
\hline 81.180 & 0.05 & 81.228 & & 14.2 & 1.4 & & 0.0085 & 0.009528 \\
\hline 82.020 & 0.06 & 82.087 & & 7.2 & 0.7 & & 0.0037 & 0.004831 \\
\hline 84.170 & & 84.214 & & 100 & & Reference $^{a}$ & 0.0671 & 0.067100 \\
\hline 89.940 & 0.05 & & & 15.3 & 1.5 & & & 0.010266 \\
\hline 92.230 & 0.05 & & -1 & 6 & 0.6 & Pa k $\alpha 2$ & & 0.004026 \\
\hline 93.300 & 0.1 & & & 0.5 & 0.05 & & & 0.000336 \\
\hline 95.870 & 0.05 & & -1 & 10.3 & 1 & Pa $k \alpha 1$ & & 0.006911 \\
\hline 99.300 & 0.05 & & & 2.1 & 0.2 & & & 0.001409 \\
\hline 102.300 & 0.05 & 102.270 & & 6.7 & 0.7 & & 0.004 & 0.004496 \\
\hline 105.730 & 0.1 & & & 0.14 & 0.02 & & & 9.39E-05 \\
\hline 106.580 & 0.1 & & & 0.34 & 0.04 & & & 0.000228 \\
\hline 107.620 & 0.1 & & -1 & 1.29 & 0.14 & Pa k $\beta 3$ & & 0.000866 \\
\hline 108.490 & 0.1 & & -1 & 2.43 & 0.24 & Pa k $\beta 1+5$ & & 0.001631 \\
\hline 111.590 & 0.1 & & -1 & 0.9 & 0.1 & Pa k $\beta 2$ & & 0.000604 \\
\hline 112.460 & 0.1 & & -1 & 0.34 & 0.04 & Pa k_0 & & 0.000228 \\
\hline 115.500 & 0.2 & & & 0.04 & 0.01 & & & $2.68 \mathrm{E}-05$ \\
\hline 116.910 & 0.05 & & & 0.39 & 0.04 & & & 0.000262 \\
\hline 125.100 & 0.05 & 124.914 & & 0.95 & 0.09 & & 0.0006 & 0.000637 \\
\hline 134.140 & 0.08 & 134.030 & & 0.42 & 0.05 & & 0.00025 & 0.000282 \\
\hline 135.770 & 0.06 & 135.664 & & 1.3 & 0.1 & & 0.00084 & 0.000872 \\
\hline 136.780 & 0.2 & & & 0.09 & 0.03 & & & $6.04 \mathrm{E}-05$ \\
\hline 145.150 & 0.3 & & & 0.12 & 0.03 & & & 8.05E-05 \\
\hline 146.000 & 0.07 & & & 0.58 & 0.06 & & & 0.000389 \\
\hline 163.160 & 0.06 & & & 2.6 & 0.03 & & & 0.001745 \\
\hline 164.940 & 0.1 & & & 0.06 & 0.03 & & & 4.03E-05 \\
\hline 169.580 & 0.1 & & & 0.03 & 0.01 & & & 2.01E-05 \\
\hline 174.190 & 0.08 & & & 0.31 & 0.03 & & & 0.000208 \\
\hline 183.470 & 0.07 & & & 0.57 & 0.06 & & & 0.000382 \\
\hline 188.770 & 0.2 & & & 0.08 & 0.01 & & & 5.37E-05 \\
\hline 218.000 & 0.07 & 217.94 & & 0.67 & 0.07 & & 0.00037 & 0.00045 \\
\hline 236.170 & 0.07 & 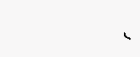 & & 0.18 & 0.02 & & & 0.000121 \\
\hline 240.400 & 0.2 & & & 0.005 & 0.0005 & & & $3.36 \mathrm{E}-06$ \\
\hline 242.600 & 0.1 & & & 0.013 & 0.0006 & & & 8.72E-06 \\
\hline 249.800 & 0.3 & & & 0.01 & 0.002 & & & $6.71 \mathrm{E}-06$ \\
\hline 250.500 & 0.3 & & & 0.011 & 0.002 & & & $7.38 \mathrm{E}-06$ \\
\hline 267.800 & 0.07 & & & 0.023 & 0.0006 & & & $1.54 \mathrm{E}-05$ \\
\hline 308.900 & 0.3 & & & 0.008 & 0.001 & & & 5.37E-06 \\
\hline 311.000 & 0.1 & & & 0.054 & 0.005 & & & 3.62E-05 \\
\hline 318.000 & 0.4 & & & 0.002 & 0.0002 & & & $1.34 \mathrm{E}-06$ \\
\hline 320.200 & 0.3 & & & 0.004 & 0.0003 & & & 2.35E-06 \\
\hline
\end{tabular}

a. Normalized to 0.0671 for $84.17 \mathrm{keV}$ transition.

b. Browne, E and Asaro F. (Phys Rev C V7n6 p2545) find the $84.17 \mathrm{keV}$ transition branching ratio $=0.070 \pm 0.003$ 
235U and Daughters Gammas

\begin{tabular}{|c|c|c|c|c|c|c|}
\hline keV & Branch ratio* & g/s/gm & Emiter1 & Parent1 & Emiter2 & Parent2 \\
\hline 11.400 & 0.03050 & $2.40 \mathrm{E}+03$ & Th-231 & U-235 & & \\
\hline 13.000 & 0.22367 & $1.76 \mathrm{E}+04$ & U-235 & U-235 & Ac-227 & U-235 \\
\hline 13.700 & 0.49817 & $3.92 \mathrm{E}+04$ & Th-231 & $\mathrm{U}-235$ & & \\
\hline 14.500 & 0.00224 & $1.76 \mathrm{E}+02$ & $\mathrm{U}-235$ & U-235 & Ac-227 & $\mathrm{U}-235$ \\
\hline 15.000 & 0.00407 & $3.20 \mathrm{E}+02$ & Th-231 & U-235 & & \\
\hline 16.100 & 0.15250 & $1.20 \mathrm{E}+04$ & U-235 & $\mathrm{U}-235$ & & \\
\hline 16.600 & 0.37617 & $2.96 \mathrm{E}+04$ & Th-231 & U-235 & & \\
\hline 17.200 & 0.00224 & $1.76 \mathrm{E}+02$ & Th-231 & U-235 & & \\
\hline 19.100 & 0.02643 & $2.08 \mathrm{E}+03$ & U-235 & U-235 & & \\
\hline 19.800 & 0.07523 & $5.92 E+03$ & Th-231 & U-235 & & \\
\hline 25.600 & 0.14869 & $1.17 \mathrm{E}+04$ & Th-231 & U-235 & & \\
\hline 42.000 & 0.00061 & $4.80 \mathrm{E}+01$ & U-235 & U-235 & & \\
\hline 42.800 & 0.00059 & $4.64 \mathrm{E}+01$ & Th-231 & U-235 & & \\
\hline 58.600 & 0.00488 & $3.84 \mathrm{E}+02$ & Th-231 & U-235 & & \\
\hline 72.700 & 0.00112 & $8.80 \mathrm{E}+01$ & U-235 & U-235 & & \\
\hline 72.800 & 0.00255 & $2.01 \mathrm{E}+02$ & Th-231 & U-235 & & \\
\hline 74.800 & 0.00061 & $4.80 \mathrm{E}+01$ & $\mathrm{U}-235$ & $\mathrm{U}-235$ & & \\
\hline 81.200 & 0.00915 & $7.20 \mathrm{E}+02$ & Th-231 & U-235 & & \\
\hline 84.200 & 0.06710 & $5.28 \mathrm{E}+03$ & Th-231 & U-235 & & \\
\hline 90.000 & 0.03419 & $2.69 E+03$ & $\mathrm{U}-235$ & U-235 & & \\
\hline 90.000 & 0.00956 & $7.52 E+02$ & Th-231 & U-235 & & \\
\hline 92.300 & 0.00397 & $3.12 \mathrm{E}+02$ & Th-231 & U-235 & & \\
\hline 93.400 & 0.05592 & $4.40 \mathrm{E}+03$ & U-235 & U-235 & & \\
\hline 95.900 & 0.00641 & $5.04 \mathrm{E}+02$ & Th-231 & U-235 & & \\
\hline 96.200 & 0.00087 & $6.88 \mathrm{E}+01$ & U-235 & U-235 & & \\
\hline 99.300 & 0.00122 & $9.60 \mathrm{E}+01$ & Th-231 & U-235 & & \\
\hline 102.300 & 0.00417 & $3.28 \mathrm{E}+02$ & Th-231 & U-235 & & \\
\hline 105.400 & 0.02008 & $1.58 \mathrm{E}+03$ & U-235 & U-235 & & \\
\hline 108.200 & 0.00231 & $1.82 \mathrm{E}+02$ & Th-231 & U-235 & & \\
\hline 109.000 & 0.00671 & $5.28 \mathrm{E}+02$ & U-235 & U-235 & & \\
\hline 109.200 & 0.01563 & $1.23 E+03$ & U-235 & U-235 & & \\
\hline 111.900 & 0.00077 & $6.08 \mathrm{E}+01$ & Th-231 & U-235 & & \\
\hline 116.100 & 0.00071 & $5.60 \mathrm{E}+01$ & $\mathrm{U}-235$ & U-235 & & \\
\hline 124.900 & 0.00057 & $4.48 \mathrm{E}+01$ & Th-231 & U-235 & & \\
\hline 135.700 & 0.00079 & $6.24 \mathrm{E}+01$ & Th-231 & U-235 & & \\
\hline 140.800 & 0.00224 & $1.76 \mathrm{E}+02$ & U-235 & U-235 & & \\
\hline 143.800 & 0.11133 & $8.76 \mathrm{E}+03$ & U-235 & U-235 & & \\
\hline 150.900 & 0.00081 & $6.40 \mathrm{E}+01$ & U-235 & U-235 & & \\
\hline 163.100 & 0.00158 & $1.24 \mathrm{E}+02$ & Th-231 & U-235 & & \\
\hline 163.300 & 0.05160 & $4.06 \mathrm{E}+03$ & U-235 & U-235 & & \\
\hline 182.600 & 0.00346 & $2.72 \mathrm{E}+02$ & U-235 & U-235 & & \\
\hline 185.700 & 0.58077 & $4.57 \mathrm{E}+04$ & U-235 & U-235 & & \\
\hline 194.900 & 0.00641 & $5.04 \mathrm{E}+02$ & U-235 & U-235 & & \\
\hline 198.900 & 0.00427 & $3.36 \mathrm{E}+02$ & U-235 & U-235 & & \\
\hline 202.100 & 0.01098 & $8.64 \mathrm{E}+02$ & U-235 & U-235 & & \\
\hline 205.300 & 0.05096 & $4.01 \mathrm{E}+03$ & U-235 & U-235 & & \\
\hline 221.400 & 0.00122 & $9.60 \mathrm{E}+01$ & U-235 & U-235 & & \\
\hline 240.900 & 0.00055 & $4.32 \mathrm{E}+01$ & $\mathrm{U}-235$ & U-235 & & \\
\hline
\end{tabular}




\section{U and Daughters Gammas}

\begin{tabular}{|c|c|c|c|c|c|}
\hline $\mathrm{E}(\mathrm{keV})$ * & $\begin{array}{c}\text { Branch Ratio } \\
\%^{*} \\
\end{array}$ & $\begin{array}{c}\text { uncert. } \\
\% *\end{array}$ & $\mathrm{~g} / \mathrm{s} / \mathrm{gm}$ & Emiter1 & Parent1 \\
\hline 63.24 & 3.6000 & 3 & $4.73 \mathrm{E}+02$ & Th-234 & U-238 \\
\hline 131.31 & 0.0286 & 1.4 & $3.23 \mathrm{E}+00$ & $\mathrm{~Pa}-234$ & U-238 \\
\hline 152.76 & 0.0083 & 3.7 & $1.08 \mathrm{E}+00$ & $\mathrm{~Pa}-234$ & U-238 \\
\hline 203.12 & 0.0027 & 8 & 3.37E-01 & $\mathrm{Pa}-234$ & U-238 \\
\hline 226.85 & 0.0167 & 1.3 & $9.54 \mathrm{E}-01$ & $\mathrm{~Pa}-234$ & U-238 \\
\hline 249.21 & 0.0035 & 4.7 & 4.53E-01 & $\mathrm{Pa}-234$ & U-238 \\
\hline 258.26 & 0.0730 & 0.46 & $9.02 \mathrm{E}+00$ & $\mathrm{~Pa}-234 \mathrm{~m}$ & U-238 \\
\hline 272.20 & 0.0018 & 9.1 & $1.62 \mathrm{E}-01$ & $\mathrm{~Pa}-234$ & U-238 \\
\hline 293.74 & 0.0049 & 3.1 & $6.31 \mathrm{E}-01$ & $\mathrm{~Pa}-234$ & $\mathrm{U}-238$ \\
\hline 369.52 & 0.0044 & 3.5 & 4.69E-01 & $\mathrm{Pa}-234$ & U-238 \\
\hline 372.02 & 0.0023 & 6.9 & $2.10 \mathrm{E}-01$ & $\mathrm{~Pa}-234$ & U-238 \\
\hline 450.96 & 0.0030 & 5.2 & $3.36 \mathrm{E}-01$ & $\mathrm{~Pa}-234 \mathrm{~m}$ & U-238 \\
\hline 453.58 & 0.0019 & 8.4 & $2.71 \mathrm{E}-01$ & $\mathrm{~Pa}-234 \mathrm{~m}$ & U-238 \\
\hline 458.63 & 0.0020 & 8 & $2.43 \mathrm{E}-01$ & $\mathrm{~Pa}-234$ & U-238 \\
\hline 468.44 & 0.0023 & 6.8 & $2.63 \mathrm{E}-01$ & $\mathrm{~Pa}-234 \mathrm{~m}$ & U-238 \\
\hline 475.75 & 0.0023 & 6.5 & $3.18 \mathrm{E}-01$ & $\mathrm{~Pa}-234 \mathrm{~m}$ & U-238 \\
\hline 506.70 & 0.0035 & 5.5 & 2.59E-01 & $\mathrm{Pa}-234$ & U-238 \\
\hline 543.98 & 0.0036 & 4.7 & 4.14E-01 & $\mathrm{Pa}-234 \mathrm{~m}$ & U-238 \\
\hline 569.30 & 0.0203 & 1.3 & $1.73 E+00$ & $\mathrm{~Pa}-234$ & U-238 \\
\hline 654.37 & 0.0022 & 7.6 & $9.70 \mathrm{E}-02$ & Pa-234 & U-238 \\
\hline 666.42 & 0.0015 & 9.8 & 2.59E-01 & $\mathrm{Pa}-234$ & U-238 \\
\hline 669.64 & 0.0017 & 8.9 & $2.26 \mathrm{E}-01$ & $\mathrm{~Pa}-234$ & U-238 \\
\hline 691.08 & 0.0090 & 2.1 & $8.75 \mathrm{E}-01$ & $\mathrm{~Pa}-234 \mathrm{~m}$ & U-238 \\
\hline 699.02 & 0.0059 & 2.6 & 7.44E-01 & $\mathrm{Pa}-234$ & U-238 \\
\hline 702.05 & 0.0071 & 2.4 & $8.59 \mathrm{E}-01$ & $\mathrm{~Pa}-234 \mathrm{~m}$ & $\mathrm{U}-238$ \\
\hline 705.90 & 0.0065 & 2.4 & $9.16 \mathrm{E}-01$ & $\mathrm{~Pa}-234$ & $\mathrm{U}-238$ \\
\hline 733.38 & 0.0115 & 1.5 & $1.39 \mathrm{E}+00$ & $\mathrm{~Pa}-234$ & U-238 \\
\hline 737.88 & 0.0021 & 8.3 & $1.62 \mathrm{E}-01$ & $\mathrm{~Pa}-234$ & U-238 \\
\hline 739.95 & 0.0118 & 2.1 & $1.13 E+00$ & $\mathrm{~Pa}-234 \mathrm{~m}$ & U-238 \\
\hline 742.77 & 0.0946 & 0.7 & $9.38 \mathrm{E}+00$ & $\mathrm{~Pa}-234 \mathrm{~m}$ & U-238 \\
\hline 755.00 & 0.0021 & 8.1 & $1.62 \mathrm{E}-01$ & $\mathrm{~Pa}-234$ & $\mathrm{U}-238$ \\
\hline 766.37 & 0.3220 & 0.65 & $3.29 \mathrm{E}+01$ & Pa-234m & U-238 \\
\hline 781.73 & 0.0078 & 2.2 & $8.43 \mathrm{E}-01$ & $\mathrm{~Pa}-234 \mathrm{~m}$ & U-238 \\
\hline 786.25 & 0.0554 & 0.93 & $5.67 \mathrm{E}+00$ & $\mathrm{~Pa}-234 \mathrm{~m}$ & U-238 \\
\hline 796.42 & 0.0054 & 4.3 & $6.14 \mathrm{E}-01$ & Pa-234 & U-238 \\
\hline 805.74 & 0.0088 & 1.8 & $1.04 \mathrm{E}+00$ & $\mathrm{~Pa}-234$ & U-238 \\
\hline 808.20 & 0.0026 & 10 & $3.60 \mathrm{E}-01$ & $\mathrm{~Pa}-234 \mathrm{~m}$ & $\mathrm{U}-238$ \\
\hline 819.21 & 0.0037 & 3.9 & $4.20 \mathrm{E}-01$ & $\mathrm{~Pa}-234$ & $\mathrm{U}-238$ \\
\hline 824.94 & 0.0068 & 2.6 & 6.47E-01 & $\mathrm{Pa}-234$ & U-238 \\
\hline 831.39 & 0.0078 & 1.9 & 8.89E-01 & $\mathrm{Pa}-234$ & $\mathrm{U}-238$ \\
\hline 851.57 & 0.0070 & 2 & $6.88 \mathrm{E}-01$ & $\mathrm{~Pa}-234 \mathrm{~m}$ & $\mathrm{U}-238$ \\
\hline 875.94 & 0.0042 & 3 & $6.47 \mathrm{E}-01$ & $\mathrm{~Pa}-234$ & $\mathrm{U}-238$ \\
\hline 880.45 & 0.0212 & 0.9 & $1.46 \mathrm{E}+00$ & $\mathrm{~Pa}-234$ & U-238 \\
\hline 883.22 & 0.0211 & 0.9 & $2.13 \mathrm{E}+00$ & $\mathrm{~Pa}-234$ & $\mathrm{U}-238$ \\
\hline 887.28 & 0.0071 & 1.8 & $8.27 \mathrm{E}-01$ & $\mathrm{~Pa}-234 \mathrm{~m}$ & U-238 \\
\hline 898.52 & 0.0059 & 2.2 & $6.63 \mathrm{E}-01$ & $\mathrm{~Pa}-234$ & $\mathrm{U}-238$ \\
\hline 921.70 & 0.0127 & 1.1 & $1.32 \mathrm{E}+00$ & $\mathrm{~Pa}-234 \mathrm{~m}$ & U-238 \\
\hline 924.98 & 0.0142 & 1.2 & $1.78 \mathrm{E}+00$ & Pa-234 & U-238 \\
\hline 926.61 & 0.0192 & 1.1 & $1.60 \mathrm{E}+00$ & $\mathrm{~Pa}-234$ & U-238 \\
\hline
\end{tabular}




\begin{tabular}{|c|c|c|c|c|c|}
\hline 941.94 & 0.0025 & 4.2 & $3.45 \mathrm{E}-01$ & $\mathrm{~Pa}-234 \mathrm{~m}$ & U-238 \\
\hline 945.90 & 0.0335 & 0.86 & $2.44 \mathrm{E}+00$ & $\mathrm{~Pa}-234$ & $\mathrm{U}-238$ \\
\hline 947.43 & 0.0031 & 4.4 & $1.29 \mathrm{E}+00$ & $\mathrm{~Pa}-234$ & U-238 \\
\hline 980.42 & 0.0045 & 3 & $4.85 \mathrm{E}-01$ & $\mathrm{~Pa}-234$ & $\mathrm{U}-238$ \\
\hline 984.09 & 0.0030 & 4.2 & 3.07E-01 & $\mathrm{Pa}-234$ & U-238 \\
\hline 994.93 & 0.0057 & 2.1 & 4.61E-01 & $\mathrm{Pa}-234 \mathrm{~m}$ & $\mathrm{U}-238$ \\
\hline 1000.99 & 0.839 & 0.56 & $1.03 E+02$ & $\mathrm{~Pa}-234 \mathrm{~m}$ & U-238 \\
\hline 1041.70 & 0.0012 & 8 & $1.54 \mathrm{E}-01$ & $\mathrm{~Pa}-234 \mathrm{~m}$ & U-238 \\
\hline 1061.89 & 0.0023 & 5.2 & $2.23 \mathrm{E}-01$ & $\mathrm{~Pa}-234 \mathrm{~m}$ & U-238 \\
\hline 1084.25 & 0.0012 & 7.5 & $2.22 \mathrm{E}-01$ & $\mathrm{~Pa}-234$ & U-238 \\
\hline 1124.93 & 0.0042 & 3.1 & 3.34E-01 & $\mathrm{Pa}-234 \mathrm{~m}$ & U-238 \\
\hline 1193.69 & 0.0135 & 0.96 & $1.43 \mathrm{E}+00$ & $\mathrm{~Pa}-234 \mathrm{~m}$ & U-238 \\
\hline 1220.37 & 0.0009 & 10.2 & 1.11E-01 & $\mathrm{Pa}-234 \mathrm{~m}$ & U-238 \\
\hline 1237.24 & 0.0053 & 1.8 & 5.73E-02 & $\mathrm{Pa}-234 \mathrm{~m}$ & $\mathrm{U}-238$ \\
\hline 1292.66 & 0.0009 & 11.2 & $9.70 \mathrm{E}-02$ & Pa-234 & U-238 \\
\hline 1352.80 & 0.0019 & 4.1 & $2.75 \mathrm{E}-01$ & Pa-234 & U-238 \\
\hline 1393.57 & 0.0039 & 2.5 & $4.85 \mathrm{E}-01$ & Pa-234 & U-238 \\
\hline 1413.88 & 0.0023 & 4.2 & $2.39 \mathrm{E}-01$ & $\mathrm{~Pa}-234 \mathrm{~m}$ & U-238 \\
\hline 1434.13 & 0.0097 & 1.3 & $9.07 \mathrm{E}-01$ & $\mathrm{~Pa}-234 \mathrm{~m}$ & U-238 \\
\hline 1452.63 & 0.0012 & 7.3 & $1.62 \mathrm{E}-01$ & Pa-234 & U-238 \\
\hline 1510.20 & 0.0129 & 1.2 & $1.45 \mathrm{E}+00$ & $\mathrm{~Pa}-234 \mathrm{~m}$ & U-238 \\
\hline 1527.27 & 0.0024 & 3.7 & 2.47E-01 & $\mathrm{Pa}-234 \mathrm{~m}$ & U-238 \\
\hline 1548.12 & 0.0014 & 5.9 & 2.07E-01 & $\mathrm{Pa}-234 \mathrm{~m}$ & U-238 \\
\hline 1553.74 & 0.0081 & 1.6 & $1.00 \mathrm{E}+00$ & $\mathrm{~Pa}-234 \mathrm{~m}$ & U-238 \\
\hline 1570.67 & 0.0011 & 7.8 & $1.21 \mathrm{E}-01$ & $\mathrm{~Pa}-234 \mathrm{~m}$ & $\mathrm{U}-238$ \\
\hline 1591.65 & 0.0019 & 5.2 & $4.30 \mathrm{E}-01$ & $\mathrm{~Pa}-234 \mathrm{~m}$ & U-238 \\
\hline 1593.88 & 0.0027 & 3.6 & $9.70 \mathrm{E}-02$ & $\mathrm{~Pa}-234$ & U-238 \\
\hline 1668.44 & 0.0012 & 6.2 & $1.94 \mathrm{E}-01$ & Pa-234 & U-238 \\
\hline 1694.08 & 0.0013 & 5.9 & $1.94 \mathrm{E}-01$ & Pa-234 & U-238 \\
\hline 1737.73 & 0.0212 & 1.1 & $2.26 \mathrm{E}+00$ & $\mathrm{~Pa}-234 \mathrm{~m}$ & U-238 \\
\hline 1759.81 & 0.0014 & 4.4 & $2.55 \mathrm{E}-01$ & $\mathrm{~Pa}-234 \mathrm{~m}$ & U-238 \\
\hline 1765.44 & 0.0087 & 1.4 & $9.71 \mathrm{E}-01$ & $\mathrm{~Pa}-234 \mathrm{~m}$ & U-238 \\
\hline 1809.04 & 0.0037 & 2.1 & $4.77 \mathrm{E}-01$ & $\mathrm{~Pa}-234 \mathrm{~m}$ & U-238 \\
\hline 1819.69 & 0.0009 & 7.3 & 1.32E-01 & $\mathrm{Pa}-234 \mathrm{~m}$ & U-238 \\
\hline 1831.36 & 0.0172 & 1.3 & $1.78 \mathrm{E}+00$ & $\mathrm{~Pa}-234 \mathrm{~m}$ & U-238 \\
\hline 1863.09 & 0.0012 & 4.3 & $1.35 \mathrm{E}-01$ & $\mathrm{~Pa}-234 \mathrm{~m}$ & U-238 \\
\hline 1867.68 & 0.0092 & 1.4 & 8.43E-01 & $\mathrm{Pa}-234 \mathrm{~m}$ & $\mathrm{U}-238$ \\
\hline 1874.85 & 0.0082 & 1.5 & 8.75E-01 & $\mathrm{Pa}-234 \mathrm{~m}$ & U-238 \\
\hline 1877.21 & 0.00165 & 3.4 & 3.07E-02 & $\mathrm{Pa}-234$ & U-238 \\
\hline 1893.50 & 0.00219 & 2.9 & $2.39 \mathrm{E}-01$ & $\mathrm{~Pa}-234 \mathrm{~m}$ & $\mathrm{U}-238$ \\
\hline 1911.17 & 0.0063 & 1.6 & $5.89 \mathrm{E}-01$ & $\mathrm{~Pa}-234 \mathrm{~m}$ & $\mathrm{U}-238$ \\
\hline 1925.42 & 0.0005 & 10.1 & $8.08 \mathrm{E}-02$ & $\mathrm{~Pa}-234$ & $\mathrm{U}-238$ \\
\hline 1937.01 & 0.0029 & 2.3 & 3.34E-01 & $\mathrm{Pa}-234 \mathrm{~m}$ & $\mathrm{U}-238$ \\
\hline
\end{tabular}

* Scott, H. L. and Marlow, K. W., NIM A286(1990) 549-55

${ }^{238} \mathrm{U}$ and Daughters- ${ }^{234} \mathrm{~Pa}$ and ${ }^{234} \mathrm{Th}$

$\begin{array}{rc}\text { E(keV) } & \text { g/s/gm } \\ 62.9 & 2.36 \\ 73.9 & 1.36 \\ 74.0 & 5.30 \\ 83.3 & 8.71\end{array}$

$\begin{array}{llll}\text { Emitter } & \text { Parent1 } & \text { Emiter2 } & \text { Parent2 } \\ \text { Th-234 } & \text { U-238 } & & \\ \text { Pa-234m } & \text { U-238 } & & \\ \text { Th-234 } & \text { U-238 } & & \\ \text { Th-234 } & \text { U-238 } & & \end{array}$




$\begin{array}{rcllll}92.3 & 338.0 & \text { Th-234 } & \text { U-238 } & & \\ 92.8 & 335.0 & \text { Th-234 } & \text { U-238 } & & \\ 94.7 & 21.6 & \text { Pa-234m } & \text { U-238 } & \text { Pa-234 } & \text { U-238 } \\ 95.9 & 1.62 & \text { Th-234 } & \text { U-238 } & & \\ 110.5 & 2.98 & \text { U-238 } & \text { U-238 } & & \\ 114.9 & 4.32 & \text { Pa-234m } & \text { U-238 } & \text { Pa-234 } & \text { U-238 } \\ 131.3 & 3.23 & \text { Pa-234 } & \text { U-238 } & & \\ 152.7 & 1.08 & \text { Pa-234 } & \text { U-238 } & & \\ 184.8 & 1.49 & \text { Th-234 } & \text { U-238 } & \\ 258.2 & 9.02 & \text { Pa-234m } & \text { U-238 } & & \end{array}$

\section{${ }^{238}$ U Daughter- Protactinium: Gammas and Branching Ratios}

\begin{tabular}{cccc}
\multicolumn{3}{c}{ 234m Pa IC-decay* } & \\
\hline E(keV) & IC-decay prob\% & \\
\hline 257.90 & 57.000 & 0.230 & Pa234m \\
691.00 & 5.500 & 0.500 & Pa234m \\
701.60 & 5.400 & 0.500 & Pa234m \\
740.10 & 7.100 & 0.700 & Pa234m \\
743.00 & 56.600 & 0.230 & Pa234m \\
766.60 & 207.800 & 0.800 & Pa234m \\
782.30 & 5.300 & 0.500 & Pa234m \\
786.40 & 34.200 & 0.130 & Pa234m \\
887.50 & 5.200 & 0.500 & Pa234m \\
922.30 & 8.300 & 0.800 & Pa234m \\
946.30 & 7.000 & 0.700 & Pa234m \\
1001.20 & 590.000 & & Pa234m \\
1738.20 & 14.200 & 0.600 & Pa234m \\
1831.50 & 11.200 & 0.400 & Pa234m \\
1868.20 & 5.300 & 0.500 & Pa234m \\
1911.80 & 3.700 & 0.400 & Pa234m \\
1937.70 & 2.100 & 0.200 & Pa234m
\end{tabular}

NORMALIZED 1001. $=590(0.59 \% \times 1000)$

* Ardisson G. and Marsol c., Nuovo Chimie 11v28A 155(75)

\begin{tabular}{ccc}
\multicolumn{2}{c}{234 Pa IC-decay ** } & \\
\hline E(keV) & IC-decay prob\% & \\
\hline 63.0 & & Pa 234 \\
131.3 & 20.00 & $\mathrm{~Pa} \mathrm{234}$ \\
153.0 & 6.60 & $\mathrm{~Pa} 234$ \\
226.9 & 11.50 & $\mathrm{~Pa} \mathrm{234}$ \\
569.3 & 13.80 & $\mathrm{~Pa} \mathrm{234}$ \\
699.1 & 4.75 & $\mathrm{~Pa} 234$ \\
805.5 & 3.10 & $\mathrm{~Pa} \mathrm{234}$ \\
824.7 & 3.70 & $\mathrm{~Pa} 234$ \\
831.1 & 5.10 & $\mathrm{~Pa} 234$ \\
926.7 & 16.80 & $\mathrm{~Pa} \mathrm{234}$ \\
945.8 & 18.40 & $\mathrm{~Pa} 234$ \\
980.5 & 3.90 & $\mathrm{~Pa} 234$ \\
1394.1 & 2.40 & $\mathrm{~Pa} \mathrm{234}$ \\
$* *$ Radiochem. Radioanal Lett. 221 357(75)
\end{tabular}




\section{Appendix D}

\section{Uranium Standard Measurements}

\begin{tabular}{|c|c|c|c|c|c|c|}
\hline \multirow{2}{*}{ U238 } & \multicolumn{4}{|c|}{ LANL Uranium Standards: mass spec. results } & \multirow{3}{*}{$\frac{\mathrm{U} 236 / 5}{\text { ratio }}$} & \multirow{3}{*}{$\frac{\mathrm{U} 234 / 6}{\text { ratio }}$} \\
\hline & $\underline{\mathbf{U} 235}$ & $\underline{\mathrm{U}-234}$ & $\mathrm{U}-236$ & $\underline{\mathbf{u} 234 / 5}$ & & \\
\hline$\%$ & $\%$ & $\%$ & $\%$ & ratio & & \\
\hline 99.275 & 0.7194 & 0.0050 & 0.0010 & 0.0070 & 0.0014 & 5.0000 \\
\hline 99.272 & 0.7225 & 0.0050 & 0.0010 & 0.0069 & 0.0014 & 5.0000 \\
\hline 99.267 & 0.7257 & 0.0050 & 0.0020 & 0.0069 & 0.0028 & 2.5000 \\
\hline 99.267 & 0.7257 & 0.0050 & 0.0020 & 0.0069 & 0.0028 & 2.5000 \\
\hline 98.024 & 1.9608 & 0.0160 & 0.0090 & 0.0082 & 0.0046 & 1.7778 \\
\hline 98.022 & 1.9632 & 0.0160 & 0.0090 & 0.0082 & 0.0046 & 1.7778 \\
\hline 96.895 & 3.0637 & 0.0250 & 0.0160 & 0.0082 & 0.0052 & 1.5625 \\
\hline 96.894 & 3.0637 & 0.0250 & 0.0170 & 0.0082 & 0.0056 & 1.4706 \\
\hline 89.664 & 10.1923 & 0.0530 & 0.0910 & 0.0052 & 0.0089 & 0.5824 \\
\hline 89.662 & 10.1961 & 0.0520 & 0.0910 & 0.0051 & 0.0089 & 0.5714 \\
\hline 89.627 & 10.2273 & 0.0540 & 0.0920 & 0.0053 & 0.0090 & 0.5870 \\
\hline 87.883 & 11.9281 & 0.0730 & 0.1160 & 0.0061 & 0.0097 & 0.6293 \\
\hline 86.730 & 13.0841 & 0.0840 & 0.1020 & 0.0064 & 0.0078 & 0.8235 \\
\hline 82.278 & 17.4129 & 0.1400 & 0.1690 & 0.0080 & 0.0097 & 0.8284 \\
\hline 72.499 & 26.9932 & 0.2370 & 0.2710 & 0.0088 & 0.0100 & 0.8745 \\
\hline 62.677 & 37.8417 & 0.2630 & 0.2180 & 0.0070 & 0.0058 & 1.2064 \\
\hline 46.749 & 52.4462 & 0.5360 & 0.2690 & 0.0102 & 0.0051 & 1.9926 \\
\hline 32.833 & 66.3254 & 0.5830 & 0.2590 & 0.0088 & 0.0039 & 2.2510 \\
\hline 7.342 & 91.4086 & 0.9150 & 0.3340 & 0.0100 & 0.0037 & 2.7395 \\
\hline
\end{tabular}

\begin{tabular}{lcccc}
$\begin{array}{l}\text { Standard } \\
\text { ID\# }\end{array}$ & $\begin{array}{c}\mathbf{U 2 3 4} \\
\text { (at. \%) }\end{array}$ & $\begin{array}{c}\mathbf{U 2 3 5} \\
\text { (at. \%) }\end{array}$ & $\begin{array}{c}\text { U236 } \\
\text { (at. \%) }\end{array}$ & $\begin{array}{c}\text { U238 } \\
\text { (at. \%) }\end{array}$ \\
\hline u0_017 & 0.0010 & 0.0170 & 0.0000 & 99.9710 \\
CRM U002 & 0.0002 & 0.0176 & 0.0000 & 99.9823 \\
u0_483 & 0.0050 & 0.4830 & 0.0008 & 99.4970 \\
NBS U-005a & 0.0034 & 0.5064 & 0.0012 & 99.4890 \\
AI-409 & 0.0050 & 0.7190 & 0.0010 & 99.3000 \\
AI-408-2 & 0.0050 & 0.7226 & 0.0010 & 99.3000 \\
AI-1127-2 & 0.0050 & 0.7256 & 0.0020 & 99.3000 \\
AI-1127-1 & 0.0050 & 0.7258 & 0.0020 & 99.3000 \\
u0_991 & 0.0080 & 0.9910 & 0.0019 & 98.9930 \\
NBS U-010 & 0.0054 & 1.0037 & 0.0068 & 98.9840 \\
AI-1125-1 & 0.0160 & 1.9610 & 0.0090 & 98.0000 \\
AI-1125-2 & 0.0160 & 1.9620 & 0.0090 & 98.0000 \\
u2_013 & 0.0160 & 2.0130 & 0.0044 & 98.0070 \\
u3_009 & 0.0310 & 3.0090 & 0.0070 & 96.9830 \\
CRM U030-A & 0.0278 & 3.0404 & 0.0006 & 96.9312 \\
AI-1126-1 & 0.0250 & 3.0630 & 0.0160 & 96.9000 \\
AI-1126-2 & 0.0250 & 3.0650 & 0.0170 & 96.9000 \\
u4_949 & 0.0410 & 4.9490 & 0.0128 & 94.9630 \\
NBS U-050 & 0.0279 & 5.0100 & 0.0480 & 94.9150 \\
U10_075 & 0.0770 & 10.0750 & 0.0299 & 89.8880 \\
CRM U100 & 0.0676 & 10.1900 & 0.0379 & 89.7040 \\
AI-324-2 & 0.0530 & 10.2000 & 0.0910 & 89.7000 \\
AI-324-1 & 0.0520 & 10.2020 & 0.0910 & 89.7000 \\
& & & & \\
& & & $-28-$ &
\end{tabular}




$\begin{array}{lllll}\text { AI-323-1 } & 0.0540 & 10.2200 & 0.0920 & 89.6000 \\ \text { UISO-12 } & 0.0730 & 11.9300 & 0.1160 & 87.8000 \\ \text { UISO-13 } & 0.0840 & 13.0890 & 0.1020 & 86.7000 \\ \text { UISO-17 } & 0.1400 & 17.4200 & 0.1690 & 82.2000 \\ \text { UISO-27 } & 0.2370 & 27.0000 & 0.2710 & 72.7000 \\ \text { UISO-38 } & 0.2630 & 37.8480 & 0.2180 & 61.6000 \\ \text { u49_38 } & 0.6720 & 49.3800 & 0.2009 & 50.0740 \\ \text { UISO-52 } & 0.5360 & 52.4260 & 0.2690 & 46.2000 \\ \text { UISO-66 } & 0.5830 & 66.3170 & 0.2590 & 32.8000 \\ \text { U75_13 } & 0.5840 & 75.1300 & 0.3320 & 23.5120 \\ \text { CRM U750 } & 0.5923 & 75.3570 & 0.2499 & 23.8010 \\ \text { UISO-91 } & 0.9150 & 91.4190 & 0.3340 & 7.3300 \\ \text { u93_076 } & 1.4520 & 93.0760 & 0.4291 & 5.4720\end{array}$


Appendix E

The approach to daughter product equilibrium.

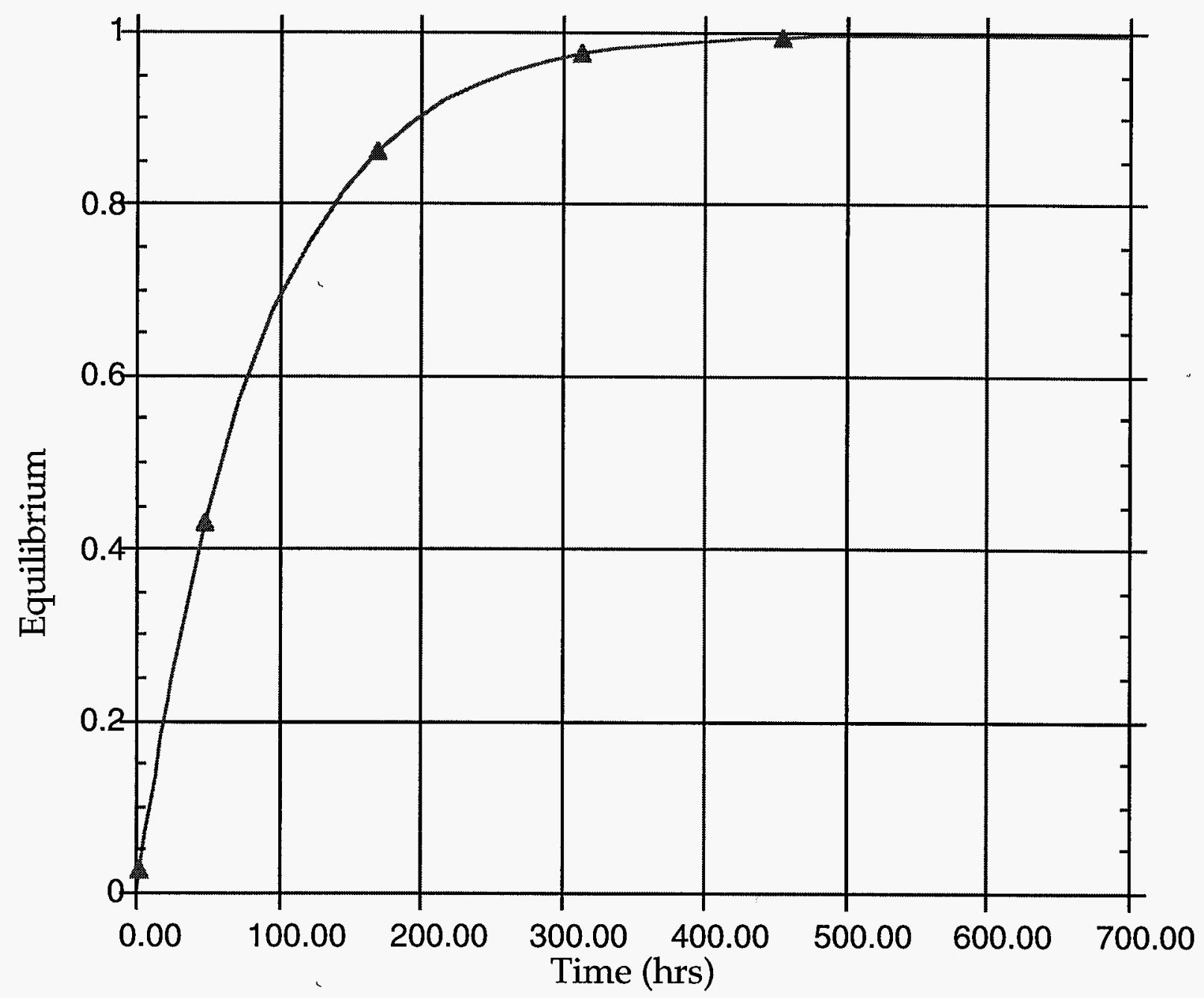

Plot of the equilibrium buildup of ${ }^{231} \mathrm{Th}\left(\mathrm{T}_{1 / 2}=25.52\right.$ hours) from the decay of $235 \mathrm{U}\left(\mathrm{T}_{1 / 2}=\right.$ $7.037 \times 10^{8}$ years). Full (99.98\% ) equilibrium is seen in 30 days. At equilibrium, $\mathrm{N}_{\mathrm{U}} \lambda_{\mathrm{U}}=\mathrm{N}_{\mathrm{Th}} \lambda_{\mathrm{Th}}$ where $N_{U}$ is the number of uranium atoms and $N_{T h}$ is the number of thorium atoms; $\lambda_{U}$ is the decay constant of ${ }^{235} \mathrm{U}$ and $\lambda_{\mathrm{Th}}$ is the decay constant of ${ }^{231} \mathrm{Th}$. At equilibrium $\mathrm{N}_{\mathrm{Th}} / \mathrm{N}_{\mathrm{U}}=4.137 \mathrm{E}-$ $12^{\mathrm{a}}$.

$$
\frac{N_{d}}{N_{p}}=\frac{\lambda_{p} \bullet N_{p}}{\lambda_{d}-\lambda_{p}} \bullet\left(e^{-\lambda_{p} t}-e^{-\lambda_{d} t}\right), \quad N_{d} \approx \frac{\lambda_{p}}{\lambda_{d}-\lambda_{p}} \bullet N_{p} e^{-\lambda_{p} t}
$$

At equilibrium

$$
N_{d} \lambda_{d}=N_{p} \lambda_{p}
$$

a. Reference: Glasstone, S., Sesonske, A., Nuclear Reactor Engineering, 3rd Ed. p42(1991) 


\section{Appendix F}

\begin{tabular}{ll}
\multicolumn{2}{c}{ Uranium } \\
\cline { 2 - 2 } Atomic number: & 92 \\
Standard atomic weight: & 238.0289 \\
Specific gravity & 18.95 \\
Symbol: & $\mathrm{U}$
\end{tabular}

\section{General information}

Standard state: solid

Color: metallic gray

Discoverer: Martin Klaproth

Date discovered: 1789

Discovered at: Germany

Meaning of name: Planet Uranus

\begin{tabular}{lcc} 
& \multicolumn{2}{c}{ Radii $(\mathrm{pm})$} \\
Atomic: & 138.5 \\
van der Waals: & & \\
Covalent: & 142 \\
Metallic: & 143 &
\end{tabular}

\section{Isotopes}

Uranium has sixteen isotopes, all of which are radioactive. Naturally occurring uranium nominally contains

$$
\begin{array}{ll}
99.28305 \% \text { by wt } & 238 \mathrm{U} \\
0.7200 \% & 235 \mathrm{U} \\
0.0054 \% & 234 \mathrm{U}
\end{array}
$$

Data for $U$; $Z=92$

\section{X-ray properties}

atomic weight $=238.070$; density $=19.0500$

K-edge at: $115.603 \mathrm{keV}$

L-edges at: $21.7560,20.9470,17.1670 \mathrm{keV}$

M-edge at: $5.54900 \mathrm{keV}$

$\mathrm{K}-\alpha 1, \mathrm{~K}-\beta$ at: $98.4280111 .289 \mathrm{keV}$

L- $\alpha, \mathrm{L}-\beta 1$ at: $13.613017 .2180 \mathrm{keV}$

K, L1, L2, L3 cross section jumps:

Inf NaN 1.410002 .29200

Fluorescence yield for K, L1, L2, L3: 0.9720, $0.1760,0.4670,0.4890$

Calculations are based on data compiled By W. H. McMaster et. al.

Fluorescence yield data by M. O. Krause, J. Phys. Chem. Ref. Data. 8, 307(1979).
Electron Configuration: -21-9-2

heat Vapor: 110

heat Fusion: 2.7

Electrical Conductivity: 0.034

Thermal Conductivity: 0.064

Specific Heat Capacity: 0.028

\begin{tabular}{ll} 
& \multicolumn{1}{c}{ Temperatures ${ }^{\circ} \mathbf{K}$} \\
melting: & 1405.5 \\
boiling: & 4028 \\
Debye: & 200 \\
superconduction: $\quad 0.68$
\end{tabular}

Uranium Isotope Properties

\begin{tabular}{lllcl} 
Z & Abund & mass (AMU) & \multicolumn{2}{c}{ half-life } \\
\hline 232 & 0 & & 69.8 & yr. \\
233 & 0 & & $1.592 \mathrm{E} 5$ & yr. \\
234 & 0.0054 & 234.040946 & $2.457 \mathrm{E} 5$ & yr. \\
235 & 0.720 & 235.043924 & $7.037 \mathrm{E} 8$ & yr. \\
236 & 0 & 236.045562 & $2.342 \mathrm{E} 7$ & yr. \\
237 & 0 & 237.04827 & 6.75 & $\mathrm{DA}$ \\
238 & 99.275 & 238.050784 & $4.468 \mathrm{E} 9$ & $\mathrm{yr}$. \\
239 & 0 & & 23.47 & $\mathrm{~min}$. \\
240 & 0 & & 14.1 & $\mathrm{hr}$
\end{tabular}

\section{2-uranium-235}

( U235 is also called actinouranium ) $\mathrm{U} 235(\mathrm{n}, \mathrm{f})$ is standard for neutrons below 20 $\mathrm{MeV}$.

Atomic Mass:

\section{General Properties}

$235.0439222 \pm 0.0000021$ AMU

Excess Mass: $40913.215 \pm 2.002 \mathrm{keV}$

Binding Energy:

$1783871.153 \pm 2.028 \mathrm{keV}$

Beta IC-decay energy: $\beta$ -

$-123.716 \pm 0.869 \mathrm{keV}$

Atomic Percent Abundance: 0.720\% Spin: 7/2-

Half life: $703.8 \mathrm{E}+6 \mathrm{Y}(0.0710 \%)$

Mode of IC-decay: Alpha to Th-231

IC-decay energy: $4.6787 \mathrm{MeV}$

Mode of IC-decay: Spontaneous fission 
Branch ratio: 7.0E-9 \%

Meta state at $0.0768 \mathrm{keV}$

Spin: $1 / 2+$

Half life: $25 \mathrm{M}$

Mode of IC-decay: Internal Transition

Total Cross Section

Cross Section at $0.0253 \mathrm{eV}=698.2 \mathrm{~b}$

Maxwell avg. at $0.0253 \mathrm{eV}=608.4 \mathrm{~b}$

Cross Section at $14 \mathrm{MeV}=5.865 \mathrm{~b}$

Fission spectrum avg. $=7.705 \mathrm{~b}$

$\mathrm{g}$-factor $=0.9833$

Elastic scattering Cross Section

Cross Section at $0.0253 \mathrm{eV}=15.04 \mathrm{~b}$

Maxwell avg. at $0.0253 \mathrm{eV}=14.95 \mathrm{~b}$

Cross Section at $14 \mathrm{MeV}=2.871 \mathrm{~b}$

Fission spectrum avg. $=4.566 \mathrm{~b}$

g-factor $=1.1215$

Total inelastic Cross Section

Cross Section at $14 \mathrm{MeV}=350.3 \mathrm{mb}$

Fission spectrum avg. $=1.804 \mathrm{~b}$

\section{(n,2n) Cross Section}

Cross Section at $14 \mathrm{MeV}=542.9 \mathrm{mb}$

Fission spectrum avg. $=11.56 \mathrm{mb}$

\section{(n,3n) Cross Section}

Cross Section at $14 \mathrm{MeV}=41.79 \mathrm{mb}$

Fission spectrum avg. $=7.074 \mu \mathrm{b}$

Total fission Cross Section

Cross Section at $0.0253 \mathrm{eV}=584.4 \mathrm{~b}$

Maxwell avg. at $0.0253 \mathrm{eV}=506.8 \mathrm{~b}$

Resonance integral $=278.1 \mathrm{~b}$

Cross Section at $14 \mathrm{MeV}=2.056 \mathrm{~b}$

Fission spectrum avg. $=1.235 \mathrm{~b}$

$\mathrm{g}$-factor $=0.9786$

\section{(n,4n) Cross Section}

Fission spectrum avg. $=0.008408 \mu \mathrm{b}$

Radiative capture Cross Section

Cross Section at $0.0253 \mathrm{eV}=98.81 \mathrm{~b}$

Maxwell avg. at $0.0253 \mathrm{eV}=86.67 \mathrm{~b}$

Resonance integral $=133.0 \mathrm{~b}$

Cross Section at $14 \mathrm{MeV}=0.1607 \mu$ barn
Fission spectrum avg. $=89.07 \mathrm{mb}$

g-factor $=0.9898$ 


\section{2-uraniùm-238}

( $238 \mathrm{U}$ is also called uranium I)

\section{General Properties}

Atomic Mass:

$238.0507835 \pm 0.0000022$ AMU

Excess Mass:

$47304.541 \pm 2.024 \mathrm{keV}$

Binding Energy:

$1801693.796 \pm 2.050 \mathrm{keV}$

Beta IC-decay energy:

$\beta--145.345 \pm 1.351 \mathrm{keV}$

Atomic Percent Abundance:

99.2745\% 15

Spin: $0+$

Half life: $4.468 \mathrm{E}+9 \mathrm{Y}(0.0671 \%)$

Mode of IC-decay: Alpha to Th-234

IC-decay energy: $4.270 \mathrm{MeV}$

Mode of IC-decay: Spontaneous fission

Branch ratio: $5.45 \times 10^{-5} \%$

Mode of IC-decay: Beta

Branch ratio: $2.2 \times 10^{-10} \%$

\section{Total Cross Section}

Cross Section at $0.0253 \mathrm{eV}=12.09 \mathrm{~b}$

Maxwell avg. at $0.0253 \mathrm{eV}=11.77 \mathrm{~b}$

Cross Section at $14 \mathrm{MeV}=5.805 \mathrm{~b}$

Fission spectrum avg. $=7.786 \mathrm{~b}$

g-factor $=1.0994$

Elastic scattering Cross Section

Cross Section at $0.0253 \mathrm{eV}=9.360 \mathrm{~b}$

Maxwell avg. at $0.0253 \mathrm{eV}=9.356 \mathrm{~b}$

Cross Section at $14 \mathrm{MeV}=2.704 \mathrm{~b}$

Fission spectrum avg. $=4.804 \mathrm{~b}$

g-factor $=1.1279$

\section{Total inelastic Cross Section}

Cross Section at $14 \mathrm{MeV}=698.3 \mathrm{mb}$

Fission spectrum avg. $=2.595 \mathrm{~b}$

\section{(n,2n) Cross Section}

Cross Section at $14 \mathrm{MeV}=910.0 \mathrm{mb}$

Fission spectrum avg. $=12.07 \mathrm{mb}$
Cross Section at $14 \mathrm{MeV}=350.0 \mathrm{mb}$

Fission spectrum avg. $=61.90 \mu$ barn

Total fission Cross Section

Cross Section at $0.0253 \mathrm{eV}=11.77 \mu$ barn

Maxwell avg. at $0.0253 \mathrm{eV}=10.45 \mu$ barn

Resonance integral $=2.020 \mathrm{~b}$

Cross Section at $14 \mathrm{MeV}=1.136 \mathrm{~b}$

Fission spectrum avg. $=308.4 \mathrm{mb}$

g-factor $=1.0015$

Radiative capture Cross Section

Cross Section at $0.0253 \mathrm{eV}=2.717 \mathrm{~b}$

Maxwell avg. at $0.0253 \mathrm{eV}=2.414 \mathrm{~b}$

Resonance integral $=278.1 \mathrm{~b}$

Cross Section at $14 \mathrm{MeV}=1.943 \mathrm{mb}$

Fission spectrum avg. $=66.40 \mathrm{mb}$

$\mathrm{g}$-factor $=1.0024$

\section{(n,3n) Cross Section}




\begin{tabular}{|c|c|c|c|c|c|c|}
\hline \multicolumn{2}{|c|}{ Isotope[1] } & \multicolumn{2}{|r|}{ delta } & \multicolumn{3}{|l|}{$\mathrm{T} 1 / 2$ or } \\
\hline Z El & $\mathbf{A}$ & Jpi[2] & $\mathrm{MeV})[3]$ & Abundance [4] & Decay Mode & \\
\hline $92 \mathrm{U}$ & 218 & $0+$ & $21.88 \mathrm{~s}$ & $1.5 \mathrm{~ms}+73-7$ & $\mathrm{~A}$ & \\
\hline & 219 & & & $23.2 \mathrm{~s}$ & 42 us $+34-13$ & $\mathrm{~A}$ \\
\hline & 220 & $0+$ & & $23.0 \mathrm{~s}$ & & \\
\hline & 221 & & & $24.5 \mathrm{~s}$ & & \\
\hline & 222 & $0+$ & & $24.3 \mathrm{~s}$ & 1.0 us $+10-4$ & $\mathrm{~A}$ \\
\hline & 223 & & & 25.82 & 18 us $+10-5$ & A \\
\hline & 224 & $0+$ & 25.70 & $1.0 \mathrm{~ms} 4$ & $\mathrm{~A}$ & \\
\hline & 225 & & & 27.37 & $95 \mathrm{~ms} 15$ & $\mathrm{~A}$ \\
\hline & 226 & $0+$ & 27.32 & $0.20 \mathrm{~s} 5$ & $\mathrm{~A}$ & \\
\hline & 227 & $(3 / 2+)$ & 29.00 & & $1.1 \mathrm{~m} 1$ & $\mathrm{~A}$ \\
\hline & 228 & $0+$ & 29.22 & & $9.1 \mathrm{~m} 2$ & $\mathrm{~A}>95 \%, \mathrm{EC}<5 \%$ \\
\hline & 229 & $(3 / 2+)$ & 31.204 & $58 \mathrm{~m} 3$ & $\mathrm{EC} \sim 80 \%, \mathrm{~A} \sim$ & $20 \%$ \\
\hline & 230 & $0+$ & 31.603 & $20.8 \mathrm{~d}$ & & $\mathrm{~A}$ \\
\hline & 231 & $(5 / 2-)$ & 33.78 & & $4.2 \mathrm{~d} 1$ & $\mathrm{EC}$ \\
\hline & 231 & $(3 / 2+, 5 / 2+$ & 33.78 & & $4.2 \mathrm{~d} 1$ & $\mathrm{~A} \sim 4 \mathrm{E}-3 \%$ \\
\hline & 232 & $0+$ & 34.601 & 68.9 y 4 & $\mathrm{~A}, \mathrm{Ne} 9 \mathrm{E}-10 \%$ & \\
\hline & 233 & $5 / 2+$ & 36.912 & $1.592 \mathrm{E}+5$ y 2 & $\begin{array}{c}\text { A,SF }<6.0 \mathrm{E}-9 \% \\
\mathrm{Ne} 7 \mathrm{E}-11 \%\end{array}$ & \\
\hline & 234 & $0+$ & 38.140 & $\begin{array}{l}2.455 E+5 \text { y } 6 \\
0.0055 \% 5\end{array}$ & $\begin{array}{l}\text { A,SF 1.7E-9\%,న } \\
\text { Ne } 9 \mathrm{E}-12 \%\end{array}$ & $\operatorname{Ig~1E-11\% ~}$ \\
\hline & 235 & $7 / 2-$ & 40.913 & $\begin{array}{l}703.8 \mathrm{E}+6 \text { y } 5 \\
0.720 \% 1\end{array}$ & A,SF $7.0 \mathrm{E}-9 \%, \mathrm{~N}$ & Je $8 E-10 \%$ \\
\hline & $235 \mathrm{M}$ & $1 / 2+$ & 40.913 & $\sim 25 \mathrm{~m}$ & IT & \\
\hline & 236 & $0+$ & 42.440 & $2.342 \mathrm{E} 7$ y 3 & $\mathrm{~A}, \mathrm{SF} 9.6 \mathrm{E}-8 \%$ & \\
\hline & $236 \mathrm{M}$ & & & 42.440 & 121 NS 2 & SF $0.013 \%$ \\
\hline & 237 & $1 / 2+$ & 45.385 & $6.75 \mathrm{~d} 1$ & B- & \\
\hline & 238 & $0+$ & 47.305 & $\begin{array}{l}4.468 \mathrm{E}+9 \text { y } 3 \\
99.2745 \% 15\end{array}$ & A,SF $0.5 \mathrm{E}-4 \%$ & \\
\hline & $238 \mathrm{M}$ & $0+$ & 47.305 & 267 NS 3 & SF $0.015 \%$ & \\
\hline & 239 & $5 / 2+$ & 50.570 & $23.45 \mathrm{~m} 2$ & B- & \\
\hline & 240 & $0+$ & 52.708 & $14.1 \mathrm{~h} 1$ & $\mathrm{~B}-, \mathrm{A}$ & \\
\hline & 242 & $0+$ & $58.830 \mathrm{C}$ & $16.8 \mathrm{~m} 5$ & B- & \\
\hline
\end{tabular}




\section{Explanation of Table}

\section{- Column 1, Isotope (Z, El, A)}

Nuclides are listed in order of increasing atomic number $(\mathrm{Z})$, and are subordered by increasing mass number (A). All isotopic species are included as well as all isomers with halflife $>$ or $=0.1 \mathrm{~s}$, and some other isomers which decay by SF or alpha emissions. A nuclide is included even if only its mass estimate or its production cross section is available. For the latter nuclides Tח limit is given[8] .

Isomeric states are denoted by the symbol " $\mathrm{m}$ " after the mass number and are given in the order of increasing excitation energy.

The $235 \mathrm{U}$ thermal fission products, with fractional cumulative yields $>$ or $=10-6$, are italicized in the table. The information on fission products is taken from the ENDF/B-VI fission products file[11].

The names for elements $\mathrm{Z}=104-109$ are those adopted by the American Chemical Society Nomenclature Committee. The symbols Rf (Rutherfordium) and Ha (Hahnium) have, not been accepted internationally due to conflicting claims about the discovery of these elements.

\section{- Column 2, Jpi}

Spin and parity assignments, without and with parentheses, are based upon strong and weak arguments, respectively. See the introductory pages of any January issue of Nuclear Data Sheets[2] for description of strong and weak arguments for Jpi assignments.

\section{- Column 3, Mass Excess, Delta}

Mass excesses, $\mathrm{M}-\mathrm{A}$, are given in $\mathrm{MeV}$ with $\operatorname{Delta}(12 \mathrm{C})=0$, by definition. For isomers the values are obtained by adding the excitation energy to the Delta(g.s.) values. Wherever the excitation energy is not known, the mass excess for the next lower isomer (or g.s.) is given. The values are given to the accuracy determined by uncertainty in Delta(g.s.) (maximum of three figures after the decimal). The uncertainty is $>$ or $=9$ in the last significant figure. An appended "s" denotes that the value is obtained from systematics.

\section{- Column 4, TП or Abundance}

The half-life and the abundance (in bold face) are shown followed by their units ("\%" symbol in the case of abundance) which are followed by the uncertainty, in italics, in the last significant figure. For example, $8.1 \mathrm{~s} 10$ means $8.1+-1.0 \mathrm{~s}$. For some very short-lived nuclei, level widths rather than half-lives are given. There also, the width is followed by units (e.g., $\mathrm{eV}, \mathrm{keV}$, or $\mathrm{MeV}$ ) which are followed by the uncertainty in Nitalics, if known.

\section{Column 5, Decay Mode}

Decay modes are given in decreasing strength from left to right, followed by the percentage branching, if known ("w" indicates a weak branch). The percentage branching is omitted where there is no competing mode of decay or no other mode has been observed. 
The various modes of decay are given below:

B-

E

IT

$\mathrm{n}, \mathrm{p}, \mathrm{A}, \ldots$

$\mathrm{SF}$

2B-, 3A, ...

B-N, B-P,

EP, EA, ESF, ... beta- decay

epsilon (electron capture), or epsilon+betat, or beta+ decay isomeric transition (through gamma or conversion-electron decay) neutron, proton, alpha, decay spontaneous fission double beta- decay (beta-beta-), decay through emission of 3 alpha's, delayed $n, p$, alpha, ... B-A, ..emission following beta decay delayed $\mathrm{p}$, alpha, SF, decay following epsilon or beta+ decay

The appendices conform to the Fundamental Physical Constants[13]. For properties of the elementary particles and for the astrophysical constants see the Review of Particle Properties, Physical Review D50, 1173 (1994) and its subsequent biennial updates. See also the World Wide Web at URL: http://pdg.lbl.gov/

\section{References:}

1. Evaluated Nuclear Structure Data File- a computer file of evaluated experimental nuclear structure data maintained by the National Nuclear Data Center, Brookhaven National Laboratory (file as of June 1995).

2. Nuclear Data Sheets - Academic Press, San Diego. Evaluations published by mass number for $A=45$ to 266 . See page ii of any issue for the index to A-chains.

3. Nuclear Physics - North Holland Publishing Co., Amsterdam - Evaluations by F. AjzenbergSelove and by D. R. Tilley, H. R. Weller, C. M. Cheves, and R. M. Chasteler for A = 3 to 20.

4. Energy Levels of A = 21-44 Nuclei (VII), P. M. Endt, Nuclear Physics A521, 1 (1990).

5. Nuclear Science Reference File- a bibliographic computer file of nuclear science references continually updated and maintained by the National Nuclear Data Center, Brookhaven National Laboratory. Recent literature scanned by S. Ramavataram.

6. Table of Isotopes (1996), 8th edition, Editors:R. B. Firestone, et al., John Wiley, New York.

7. Spontaneous Fission, D. C. Hoffman, T. M. Hamilton, and M. R. Lane, Rept. LBL-33001 (1992).

8. NUBASE: A Database of Nuclear and Decay Properties, G. Audi, O. Bersillon, J. Blachot, and A. H. Wapstra, Intl. Symposium on Radionuclide Metrology and its Applications (1995).

9. The 1993 Atomic Mass Evaluation, G. Audi and A. H. Wapstra, computerized list of recommended values based on authors' publication Nuclear Physics A565, 1 (1993)

10. Table of the Isotopes, N. E. Holden, Rept BNL-61460 (1995) and private communication.

11. Evaluation and Compilation of Fission Product Yields 1993, T. R. England and B. F. Rider; Rept. LA-UR-94-3106 (1994). ENDF/B-VI evaluation; MAT \#9228, Revision 1.

12. Table of Isotopes (1978), 7th edition, Editors: C. M. Lederer, V. S. Shirley, Authors: E. Browne, J. M. Dairiki, R. E. Doebler, A. A. Shihab-Eldin, J. Jardine, J. K. Tuli, and A. B. Buyrn, John Wiley, New York.

13. The Fundamental Physical Constants, E. R. Taylor and B. N. Taylor, Physics Today BG9 (August, 1995). 
Technical Information Department • Lawrence Livermore National Laboratory University of California • Livermore, California 94551

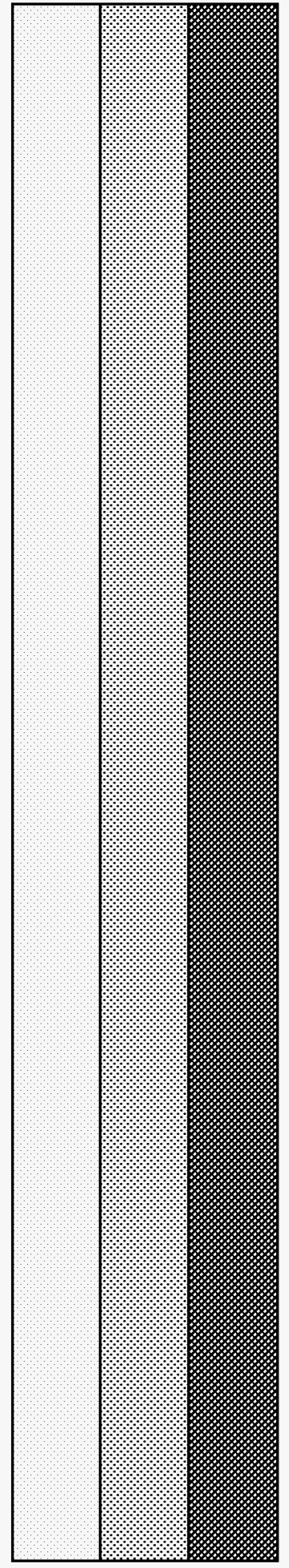

